\title{
Identification of microRNAs associated with the aggressiveness of prolactin pituitary tumors using bioinformatic analysis
}

\author{
ZIHAO WANG ${ }^{1,2}$, LU GAO $^{1,2}$, XIAOPENG GUO ${ }^{1,2}$, CHENZHE FENG $^{1,2}$, \\ KAN DENG $^{1,2}$, WEI LIAN ${ }^{1,2}$ and BING XING ${ }^{1,2}$ \\ ${ }^{1}$ Department of Neurosurgery, Peking Union Medical College Hospital, Chinese Academy of Medical Sciences \\ and Peking Union Medical College, Dongcheng; ${ }^{2}$ China Pituitary Disease Registry Center, \\ Chinese Pituitary Adenoma Cooperative Group, Dongcheng, Beijing 100730, P.R. China
}

Received January 15, 2019; Accepted May 23, 2019

DOI: $10.3892 /$ or.2019.7173

\begin{abstract}
Aggressive prolactin pituitary tumors, which exhibit aggressive behaviors and resistance to conventional treatments, are a huge challenge for neurosurgeons. Many studies have investigated the roles of microRNAs (miRNAs) in pituitary tumorigenesis, invasion and metastasis, but few have explored aggressiveness-associated miRNAs in aggressive pituitary tumors. Differentially expressed miRNAs (DEMs) between aggressive and nonaggressive prolactin pituitary tumors were screened using the GSE46294 miRNA expression profile downloaded from the GEO database. The potential target genes of the top three most highly upregulated and downregulated DEMs were predicted by miRTarBase, and potential functional annotation and pathway enrichment analysis were performed using the DAVID database. Protein-protein interaction (PPI) and miRNA-hub gene interaction networks were constructed by Cytoscape software. A total of 43 DEMs were identified, including 19 upregulated and 24 downregulated miRNAs, between aggressive and
\end{abstract}

Correspondence to: Dr Bing Xing, Department of Neurosurgery, Peking Union Medical College Hospital, Chinese Academy of Medical Sciences and Peking Union Medical College, 1 Shuaifuyuan, Dongcheng, Beijing 100730, P.R. China

E-mail: xingbingemail@aliyun.com

Abbreviations: miRNAs, microRNAs; DEMs, differentially expressed miRNAs; PPI, protein-protein interaction; TMZ, temozolomide; mRNA, messenger RNA; DE-miRNAs, differentially expressed miRNAs; GO, Gene Ontology; KEGG, Kyoto Encyclopedia of Genes and Genomes; GEO, Gene Expression Omnibus; DAVID, Database for Annotation, Visualization and Integrated Discovery; MCODE, Molecular Complex Detection; BiNGO, Biological Networks Gene Oncology tool; BP, biological process; CC, cellular component; MF, molecular function; EGFR, epidermal growth factor receptor; EGF, epidermal growth factor; TKI, tyrosine kinase inhibitor

Key words: aggressive pituitary tumor, pituitary carcinoma, prolactinoma, microRNA, bioinformatic analysis nonaggressive prolactin pituitary tumors. One hundred and seventy and 680 target genes were predicted for the top three most highly upregulated and downregulated miRNAs, respectively, and these genes were involved in functional enrichment pathways, such as regulation of transcription from RNA polymerase II promoter, DNA-templated transcription, Wnt signaling pathway, protein binding, and transcription factor activity (sequence-specific DNA binding). In the PPI network, the top 10 genes with the highest degree of connectivity of the upregulated and downregulated DEMs were selected as hub genes. By constructing an miRNA-hub gene network, it was found that most hub genes were potentially modulated by hsa-miR-489 and hsa-miR-520b. Targeting hsa-miR-489 and hsa-miR-520b may provide new clues for the diagnosis and treatment of aggressive prolactin pituitary tumors.

\section{Introduction}

Pituitary tumors represent approximately $10-15 \%$ of intracranial tumors, of which prolactin-secreting pituitary adenomas (prolactinoma) are the most common subtypes, accounting for $30-40 \%$ of pituitary tumors $(1,2)$. Most of these tumors are noninvasive, show slow growth and are easily treated by surgery or medical treatment, including cabergoline and dopamine agonists. However, a small subset, accounting for $2.5-10 \%$ of pituitary adenomas, are defined as aggressive pituitary tumors and can exhibit aggressive behaviors, resistance to conventional treatments and/or temozolomide (TMZ), and multiple recurrences despite standard therapies combining surgical, medical and radiotherapy treatment approaches $(3,4)$. Early identification of aggressive pituitary tumors is challenging but is of major clinical importance as these tumors are associated with increased morbidity and mortality (5). Numerous studies have been performed to explore potential predictive and prognostic biomarkers for the molecular pathogenesis underlying the aggressive behavior and malignant transformation of pituitary tumors, yet research results remain fairly unreliable and controversial $(4,6,7)$.

MicroRNAs (miRNAs/miRs) are a large family of short endogenous noncoding RNAs, approximately 21-25 nucleotides 
in length, that can directly bind to the 3'-untranslated region of messenger RNA (mRNA), thereby leading to suppression of protein translation or mRNA degradation $(8,9)$. Subsequently, miRNAs can negatively regulate the expression of target genes involved in proliferation, apoptosis, cell cycle differentiation, invasion and metabolism (9). Aberrant expression of miRNAs contributes to tumorigenesis, invasion and metastasis by derepressing or silencing key regulatory proteins in various types of tumors, including pituitary adenomas (10-12). Many studies have investigated the roles of miRNAs in pituitary tumorigenesis, dysfunction, neurodegeneration and metastasis by comparing tumoral to normal pituitary tissues (13-16). However, currently, there are few studies that have explored aggressiveness-associated miRNAs in 'aggressive' pituitary tumors, especially aggressive prolactinoma, one of the most common subtypes of pituitary adenomas, based on large-scale human tissue datasets.

In recent years, microarray technology and bioinformatic analysis have been widely used to help us discover novel clues to identify reliable and functional miRNAs. In the present study, differentially expressed miRNAs (DEMs, DE-miRNAs) between aggressive and nonaggressive prolactin pituitary tumors were screened using the GSE46294 miRNA expression profile (17). The potential target genes of the top three most highly upregulated and downregulated DE-miRNAs were predicted by miRTarBase. Subsequently, Gene Ontology (GO), Kyoto Encyclopedia of Genes and Genomes (KEGG) pathway enrichment and protein-protein interaction (PPI) network analyses were performed to help us understand the molecular mechanisms underlying the aggressiveness of pituitary tumors. Finally, 20 hub genes were identified, and an miRNA-hub gene network was constructed by Cytoscape software. In conclusion, our study aimed to explore the aggressiveness-associated miRNAs in aggressive prolactin pituitary tumors and their potential molecular mechanisms based on bioinformatic analysis and to provide candidate biomarkers for early diagnosis and individualized treatment of aggressive prolactin pituitary tumors.

\section{Materials and methods}

Microarray data. The Gene Expression Omnibus (GEO, http://www.ncbi.nlm.nih.gov/geo/) is a public functional genomics data repository of high-throughput gene expression data, chips and microarrays (18). After extensive data screening in the GEO database, only the GSE46294 dataset was selected as it compared the miRNA expression of aggressive and nonaggressive prolactin pituitary tumors (17). GSE46294, based on the GPL13264 platform (Agilent-021827 Human miRNA Microarray), contained four aggressive prolactin pituitary tumor samples and eight nonaggressive prolactin pituitary tumor samples.

Data processing. GEO2R (http://www.ncbi.nlm.nih.gov/ geo/geo2r/) is an interactive web tool that can compare different groups of samples from the GEO series to identify DEMs across experimental conditions (19). The DEMs between aggressive and nonaggressive prolactin pituitary tumor samples were screened using GEO2R. Adjusted P-values (adj. P) were applied to correct the false-positive results by using the default
Benjamini-Hochberg false discovery rate method. Adj. $\mathrm{P}<0.01$ and Ifold change (FC)| $>2$ were considered the cut-off values for identifying DEMs. A DEM hierarchical clustering heat map was constructed using $\mathrm{MeV}$ (Multiple Experiment Viewer, http://mev.tm4.org/), which is a cloud-based application supporting the analysis, visualization, and stratification of large genomic data, particularly RNASeq and microarray data. The potential target genes of the top three most highly upregulated and downregulated DE-miRNAs were predicted by miRTarBase (http://mirtarbase.mbc.nctu.edu.tw/php/index. $\mathrm{php} /$ ), which is a database for experimentally validated miRNA-target interactions (20).

Functional and pathway enrichment analyses. The Database for Annotation, Visualization and Integrated Discovery (DAVID, http://david.ncifcrf.gov/) is an online tool for gene functional classification, which is an essential foundation for high-throughput gene analysis to understand the biological significance of genes (21). DAVID was introduced to perform functional annotation and pathway enrichment analysis, including GO (Gene Ontology) enrichment and KEGG (Kyoto Encyclopedia of Genes and Genomes) pathway analysis, for the predicted target genes of 6 selected DEMs $(22,23)$. A P-value $<0.05$ was considered statistically significant.

PPI network construction and module analysis. The target genes obtained from the upregulated and downregulated DEMs were first mapped to the STRING database (http://string-db. org) to assess functional associations among these target genes, with a combined score $>0.4$ defined as significant (24). Then, PPI networks were constructed using Cytoscape, which is a biological graph visualization software for integrated models of biologic molecular interaction networks (25). The Molecular Complex Detection (MCODE) plugin of Cytoscape was used to identify the most significant module in the PPI networks (26). The criteria for selection were as follows: Degree cut-off $=2$, node score cut-off $=0.2$, maximum depth $=100$ and $\mathrm{k}$-core $=2$. Moreover, GO and KEGG enrichment analyses were performed using DAVID for genes in the modules.

Hub gene analysis and miRNA-hub gene network construction . Hub genes were selected by considering the high degree of connectivity in the PPI networks analyzed by the cytohubba plugin of Cytoscape. The top 10 genes with the highest degree of connectivity were selected as the hub genes of the upregulated and downregulated DEMs, respectively. Subsequently, GO and KEGG enrichment analyses were performed for the selected 20 hub genes. The biological process analysis of hub genes was performed and visualized using the Biological Networks Gene Oncology tool (BiNGO) plugin of Cytoscape (27). The latest information of functional roles of hub genes was downloaded from GeneCards in Nov. 2018 (https://www.genecards.org/). Subsequently, an miRNA-hub gene network was constructed by Cytoscape.

\section{Results}

Identification of DEMs and their target genes. Following analysis of the GSE46294 dataset using GEO2R, a total 
Table I. Top 10 upregulated and downregulated DEMs between aggressive and nonaggressive prolactin pituitary tumors.

\begin{tabular}{lllll}
\hline miRNAs (DEMs) & P-value & $\mathrm{t}$ & $\mathrm{B}$ & $\operatorname{logFC}$ \\
\hline Upregulated & & & & \\
hsa-miR-489 & 0.00677 & 3.25 & -4.58 & 7.07 \\
hsa-let-7d* & 0.02591 & 2.53 & -4.58 & 6.09 \\
hsa-miR-138-1* & 0.02569 & 2.54 & -4.58 & 5.26 \\
hsa-miR-886-3p & 0.00191 & 3.94 & -4.58 & 4.36 \\
hsa-miR-576-5p & 0.04773 & 2.2 & -4.59 & 3.83 \\
hsa-miR-135b & 0.01671 & 2.77 & -4.58 & 3.72 \\
hsa-miR-137 & 0.03877 & 2.32 & -4.59 & 3.29 \\
hsa-miR-886-3p & 0.00235 & 3.82 & -4.58 & 3.2 \\
hsa-miR-551b & 0.02074 & 2.66 & -4.58 & 3.04 \\
hsa-miR-296-3p & 0.04524 & 2.23 & -4.59 & 3.02 \\
Downregulated & & & & \\
hsa-miR-520b & 0.00732 & -3.21 & -4.58 & -6.36 \\
hsa-miR-875-5p & 0.04037 & -2.29 & -4.59 & -5.66 \\
hsa-miR-671-3p & 0.01453 & -2.85 & -4.58 & -5.49 \\
hsa-miR-372 & 0.00348 & -3.61 & -4.58 & -5.49 \\
hsa-miR-586 & 0.02631 & -2.53 & -4.58 & -5.44 \\
hsa-miR-367* & 0.02421 & -2.57 & -4.58 & -4.84 \\
hsa-miR-302b & 0.01052 & -3.02 & -4.58 & -4.49 \\
hsa-miR-187 & 0.0322 & -2.42 & -4.59 & -4.35 \\
hsa-miR-193b* & 0.02207 & -2.62 & -4.58 & -4.31 \\
hsa-miR-452* & 0.00322 & -3.65 & -4.58 & -4.17 \\
\hline
\end{tabular}

miRNA names with '*' are also mature miRNAs as annotated in miRBase (http://www.mirbase.org). For example, hsa-let-7d* is hsa-let-7d-3p; hsa-miR-138-1* is hsa-miR-138-1-3p; hsa-miR-367* is hsa-miR-367-5p; hsa-miR-193b* is hsa-miR-193b-5p; hsa-miR-452* is hsa-miR-452-3p. DEMs, differentially expressed miRNAs; hsa, Homo sapiens.

of 43 DEMs were identified, including 19 upregulated and 24 downregulated miRNAs between aggressive and nonaggressive prolactin pituitary tumors. For better visualization, the top 10 most highly upregulated miRNAs and the top 10 most highly downregulated miRNAs are presented in Table I, and the hierarchical clustering heat map of the DEMs is presented in Fig. S1. According to their FC values, hsa-miR-489, hsa-let-7d* and hsa-miR-138-1* were the top 3 most highly upregulated miRNAs, and hsa-miR-520b, hsa-miR-875-5p and hsa-miR-671-3p were the top 3 most highly downregulated miRNAs (Table I). One hundred seventy potential target genes were predicted for the top 3 most highly upregulated miRNAs and 680 potential target genes were predicted for the top 3 most highly downregulated miRNAs by miRTarBase.

Functional and pathway enrichment analyses. GO analysis, including biological process (BP), cellular component (CC) and molecular function (MF), was performed on the potential target genes of top 3 most highly upregulated miRNAs (Table II) and the top 3 most highly downregulated miRNAs
(Table III). GO functional annotation analysis showed that in the BP category, the target genes of the top 3 most highly upregulated miRNAs were significantly enriched in DNA-templated transcription, signal transduction, and positive regulation of transcription from RNA polymerase II promoter (Fig. 1A), while the target genes of the top 3 most highly downregulated miRNAs were enriched in DNA-templated transcription, DNA-templated regulation of transcription, and regulation of transcription from RNA polymerase II promoter (Fig. 1B). In the CC category, the target genes of the top three most highly upregulated miRNAs were significantly enriched in cytoplasm, nucleus and cytosol (Fig. 2A), while the target genes of the top three most highly downregulated miRNAs were enriched in nucleus, nucleoplasm and cytosol (Fig. 2B). In the MF category, the target genes of the top 3 most highly upregulated miRNAs were significantly enriched in protein binding, transcription factor activity, sequence-specific DNA binding, transcriptional activator activity, and RNA polymerase II core promoter proximal region sequence-specific binding (Fig. 3A), while the target genes of the top 3 most highly downregulated miRNAs were enriched in protein binding, DNA binding and transcription factor activity, and sequence-specific DNA binding (Fig. 3B). In addition, KEGG pathway analysis revealed that the target genes of the top 3 most highly upregulated miRNAs were mainly enriched in the Wnt signaling pathway, cGMP-PKG signaling pathway and renal cell carcinoma (Fig. 4A), while the target genes of the top three most highly downregulated miRNAs were mainly enriched in pathways in cancer, proteoglycans in cancer, measles and influenza A (Fig. 4B) (Tables II and III).

PPI network construction and module analysis. The PPI networks of the target genes of the top 3 most highly upregulated and downregulated DEMs were constructed (Fig. 5), and the most significant module was obtained using the MCODE plugin of Cytoscape. The genes in the most significant module of the upregulated DEMs were $S F 1, S N R P D 3$ and SNRPA1, while the genes in the most significant module of the downregulated DEMs were $R N F 34, R N F 19 B, A S B 16$, FBXL7, UBE2V2, RBBP6, KBTBD6, WSB1, KLHL21, CUL3, $T C E B 1, U B O X 5$ and $R N F 115$. Functional analyses of the genes involved in the module of the downregulated DEMs were performed using DAVID, showing that genes in this module were mainly enriched in protein K48-linked ubiquitination (BP), polar microtubule (CC), ubiquitin-protein transferase activity (MF), and ubiquitin-mediated proteolysis(KEGG).

Hub gene analysis and miRNA-hub gene network construction. For the upregulated miRNAs, the hub genes included RHOB, PTPN11, SNAI2, UBE2D1, SF1, PDPN, NUP43, YY1, HIFIA and SNRPD3. For the downregulated miRNAs, the hub genes were EGFR, CTNNB1, ESR1, CDKN1A, CCND1, CYCS, DNAJC10,IL8,CUL3 and $I G F 1 R$. The abbreviations, full names and functions of these 20 hub genes are shown in Table IV. Among these genes, $E G F R$ (epidermal growth factor receptor) demonstrated the highest node degrees, which suggested that EGFR may be a key target associated with prolactin pituitary tumor 
Table II. Functional and pathway enrichment analysis for target genes of the top 3 upregulated miRNAs.

\begin{tabular}{|c|c|c|c|c|}
\hline Category & Term & Pathway description & Count & P-value \\
\hline \multicolumn{5}{|c|}{ Upregulated miRNAs } \\
\hline GO BP & GO:0060412 & Ventricular septum morphogenesis & 3 & 0.020464503 \\
\hline GO BP & GO:0007286 & Spermatid development & 4 & 0.021020749 \\
\hline GO BP & GO:0000122 & $\begin{array}{l}\text { Negative regulation of transcription from RNA } \\
\text { polymerase II promoter }\end{array}$ & 12 & 0.021742388 \\
\hline GO BP & GO:0006351 & Transcription, DNA-templated & 24 & 0.022393279 \\
\hline GO BP & GO:0030154 & Cell differentiation & 9 & 0.025194909 \\
\hline GO BP & GO:0097411 & Hypoxia-inducible factor- $1 \alpha$ signaling pathway & 2 & 0.030146509 \\
\hline GO BP & GO:0030177 & Positive regulation of Wnt signaling pathway & 3 & 0.030678983 \\
\hline GO BP & GO:0007165 & Signal transduction & 16 & 0.030948235 \\
\hline GO BP & GO:0030336 & Negative regulation of cell migration & 4 & 0.036066871 \\
\hline GO BP & GO:0045944 & $\begin{array}{l}\text { Positive regulation of transcription from RNA } \\
\text { polymerase II promoter }\end{array}$ & 14 & 0.03646379 \\
\hline $\mathrm{GO} \mathrm{CC}$ & GO:0005737 & Cytoplasm & 52 & 0.0134897 \\
\hline $\mathrm{GO} \mathrm{CC}$ & GO:0031519 & PcG protein complex & 3 & 0.016939042 \\
\hline $\mathrm{GO} \mathrm{CC}$ & GO:0005634 & Nucleus & 52 & 0.026624876 \\
\hline $\mathrm{GO} \mathrm{CC}$ & GO:0005794 & Golgi apparatus & 13 & 0.026655792 \\
\hline $\mathrm{GO} \mathrm{CC}$ & GO:0005654 & Nucleoplasm & 29 & 0.053523267 \\
\hline $\mathrm{GO} \mathrm{CC}$ & GO:0031526 & Brush border membrane & 3 & 0.054869988 \\
\hline $\mathrm{GO} \mathrm{CC}$ & GO:0000139 & Golgi membrane & 9 & 0.072820488 \\
\hline $\mathrm{GO} \mathrm{CC}$ & GO:0044798 & Nuclear transcription factor complex & 2 & 0.078554642 \\
\hline $\mathrm{GO} \mathrm{CC}$ & GO:0005829 & Cytosol & 32 & 0.094144731 \\
\hline GO MF & GO:0005515 & Protein binding & 83 & 0.007060503 \\
\hline GO MF & GO:0050693 & LBD domain binding & 2 & 0.030452531 \\
\hline GO MF & GO:0003700 & $\begin{array}{l}\text { Transcription factor activity, sequence-specific } \\
\text { DNA binding }\end{array}$ & 14 & 0.034027538 \\
\hline GO MF & GO:0001077 & $\begin{array}{l}\text { Transcriptional activator activity, RNA } \\
\text { polymerase II core sequence-specific binding }\end{array}$ & 6 & 0.035934263 \\
\hline GO MF & GO:0030620 & U2 snRNA binding & 2 & 0.045331887 \\
\hline GO MF & GO:0008517 & Folic acid transporter activity & 2 & 0.052686367 \\
\hline GO MF & GO:0001078 & $\begin{array}{l}\text { Transcriptional repressor activity, RNA } \\
\text { polymerase II core promoter proximal region } \\
\text { sequence-specific binding }\end{array}$ & 4 & 0.054345955 \\
\hline GO MF & GO:0004726 & $\begin{array}{l}\text { Non-membrane spanning protein tyrosine } \\
\text { phosphatase activity }\end{array}$ & 2 & 0.059984623 \\
\hline GO MF & GO:0003714 & Transcription corepressor activity & 5 & 0.071931973 \\
\hline GO MF & GO:0004871 & Signal transducer activity & 5 & 0.07295342 \\
\hline KEGG & hsa04310 & Wnt signaling pathway & 5 & 0.006641183 \\
\hline KEGG & hsa04022 & cGMP-PKG signaling pathway & 5 & 0.01255563 \\
\hline KEGG & hsa05211 & Renal cell carcinoma & 3 & 0.049309583 \\
\hline
\end{tabular}

In the event there were more than five terms enriched in this category, the top 5 terms were selected per P-value. GO, Gene Ontology; $\mathrm{BP}$, biological process; CC, cellular component; MF, molecular function; KEGG, Kyoto Encyclopedia of Genes and Genomes; Count, numbers of enriched genes in each term; hsa, Homo sapiens.

aggressiveness. Biological process analysis of the hub genes is shown in Fig. 6A. Functional and pathway enrichment analyses for the hub genes of the top 3 upregulated and downregulated miRNAs are presented in Tables V and VI. As shown in Fig. 6, KEGG analysis showed that the hub genes of the upregulated miRNAs were mainly enriched in renal cell carcinoma and proteoglycans in cancer (Fig. 6B, Table V), while the hub genes of the downregulated miRNAs were mainly enriched in proteoglycans in cancer, prostate cancer and pathways in cancer (Fig. 6C, Table VI). 
Table III. Functional and pathway enrichment analysis for target genes of the top 3 downregulated miRNAs.

\begin{tabular}{|c|c|c|c|c|}
\hline Category & Term & Description & Count & P-value \\
\hline \multicolumn{5}{|c|}{ Downregulated miRNAs } \\
\hline GO BP & GO:0046777 & Protein autophosphorylation & 15 & 0.000170888 \\
\hline GO BP & GO:0006355 & $\begin{array}{l}\text { Regulation of transcription, } \\
\text { DNA-templated }\end{array}$ & 59 & 0.001639464 \\
\hline GO BP & GO:0006357 & $\begin{array}{l}\text { Regulation of transcription from RNA } \\
\text { polymerase II promoter }\end{array}$ & 23 & 0.002882721 \\
\hline GO BP & GO:0016567 & Protein ubiquitination & 20 & 0.002898481 \\
\hline GO BP & GO:0006351 & Transcription, DNA-templated & 71 & 0.003602574 \\
\hline GO BP & GO:0006123 & $\begin{array}{l}\text { Mitochondrial electron transport, } \\
\text { cytochrome } c \text { to oxygen }\end{array}$ & 4 & 0.014446477 \\
\hline GO BP & GO:0042119 & Neutrophil activation & 3 & 0.017126856 \\
\hline GO BP & GO:0007223 & $\begin{array}{l}\text { Wnt signaling pathway, calcium } \\
\text { modulating pathway }\end{array}$ & 5 & 0.018278676 \\
\hline GO BP & GO:0008654 & Phospholipid biosynthetic process & 5 & 0.019902891 \\
\hline GO BP & GO:0048468 & Cell development & 5 & 0.019902891 \\
\hline $\mathrm{GO} \mathrm{CC}$ & GO:0005654 & Nucleoplasm & 112 & $6.68468 \mathrm{E}-07$ \\
\hline $\mathrm{GO} \mathrm{CC}$ & GO:0005634 & Nucleus & 170 & 0.001202665 \\
\hline $\mathrm{GO} \mathrm{CC}$ & GO:0017053 & Transcriptional repressor complex & 7 & 0.002719148 \\
\hline GO CC & GO:0005758 & Mitochondrial intermembrane space & 8 & 0.002811554 \\
\hline $\mathrm{GO} \mathrm{CC}$ & GO:0005813 & Centrosome & 22 & 0.003323275 \\
\hline $\mathrm{GO} \mathrm{CC}$ & GO:0005739 & Mitochondrion & 50 & 0.006368195 \\
\hline $\mathrm{GO} \mathrm{CC}$ & GO:0031463 & Cul3-RING ubiquitin ligase complex & 7 & 0.007248149 \\
\hline $\mathrm{GO} \mathrm{CC}$ & GO:0005829 & Cytosol & 106 & 0.009417134 \\
\hline $\mathrm{GO} \mathrm{CC}$ & GO:0015629 & Actin cytoskeleton & 13 & 0.010602362 \\
\hline $\mathrm{GO} \mathrm{CC}$ & GO:0005741 & Mitochondrial outer membrane & 10 & 0.014535489 \\
\hline GO MF & GO:0005515 & Protein binding & 269 & $9.14069 \mathrm{E}-05$ \\
\hline GO MF & GO:0003677 & DNA binding & 62 & 0.004456722 \\
\hline GO MF & GO:0004842 & Ubiquitin-protein transferase activity & 18 & 0.005935513 \\
\hline GO MF & GO:0003700 & $\begin{array}{l}\text { Transcription factor activity, } \\
\text { sequence-specific DNA binding }\end{array}$ & 39 & 0.006954496 \\
\hline $\mathrm{GO} \mathrm{MF}$ & GO:0004672 & Protein kinase activity & 18 & 0.013435998 \\
\hline GO MF & GO:0004879 & $\begin{array}{l}\text { RNA polymerase II transcription factor } \\
\text { activity, ligand-activated sequence-specific } \\
\text { DNA binding }\end{array}$ & 5 & 0.013877869 \\
\hline GO MF & GO:0003707 & Steroid hormone receptor activity & 6 & 0.015112205 \\
\hline GO MF & GO:0043565 & Sequence-specific DNA binding & 23 & 0.017535243 \\
\hline GO MF & GO:0031625 & Ubiquitin protein ligase binding & 15 & 0.018757483 \\
\hline GO MF & GO:0004674 & Protein serine/threonine kinase activity & 18 & 0.020173241 \\
\hline KEGG & hsa05162 & Measles & 10 & 0.005987506 \\
\hline KEGG & hsa05215 & Prostate cancer & 8 & 0.006312095 \\
\hline KEGG & hsa05200 & Pathways in cancer & 19 & 0.009215433 \\
\hline KEGG & hsa05205 & Proteoglycans in cancer & 12 & 0.011467731 \\
\hline KEGG & hsa05219 & Bladder cancer & 5 & 0.018691786 \\
\hline KEGG & hsa04962 & Vasopressin-regulated water reabsorption & 5 & 0.023655555 \\
\hline KEGG & hsa04919 & Thyroid hormone signaling pathway & 8 & 0.023895596 \\
\hline KEGG & hsa05164 & Iinfluenza A & 10 & 0.030429321 \\
\hline KEGG & hsa05218 & Melanoma & 6 & 0.032052212 \\
\hline KEGG & hsa04390 & Hippo signaling pathway & 9 & 0.035379929 \\
\hline
\end{tabular}

If there were more than five terms enriched in this category, the top 5 terms were selected per the P-value. GO, Gene Ontology; BP, biological process; CC, cellular component; MF, molecular function; KEGG, Kyoto Encyclopedia of Genes and Genomes; Count, numbers of enriched genes in each term; hsa, Homo sapiens. 
A

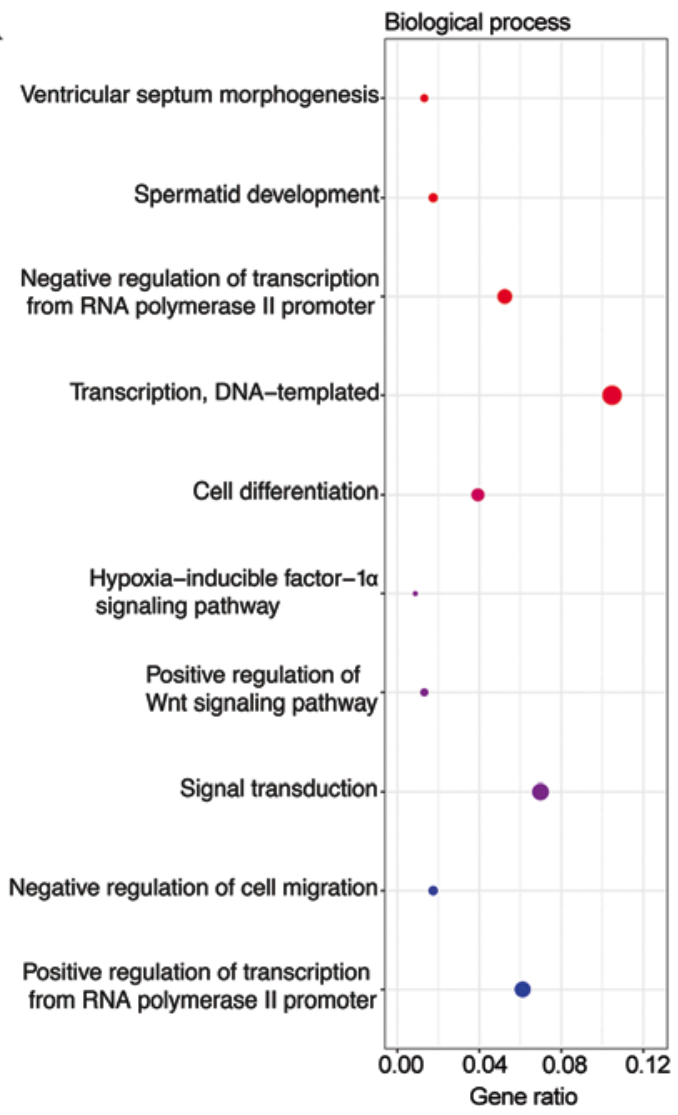

B

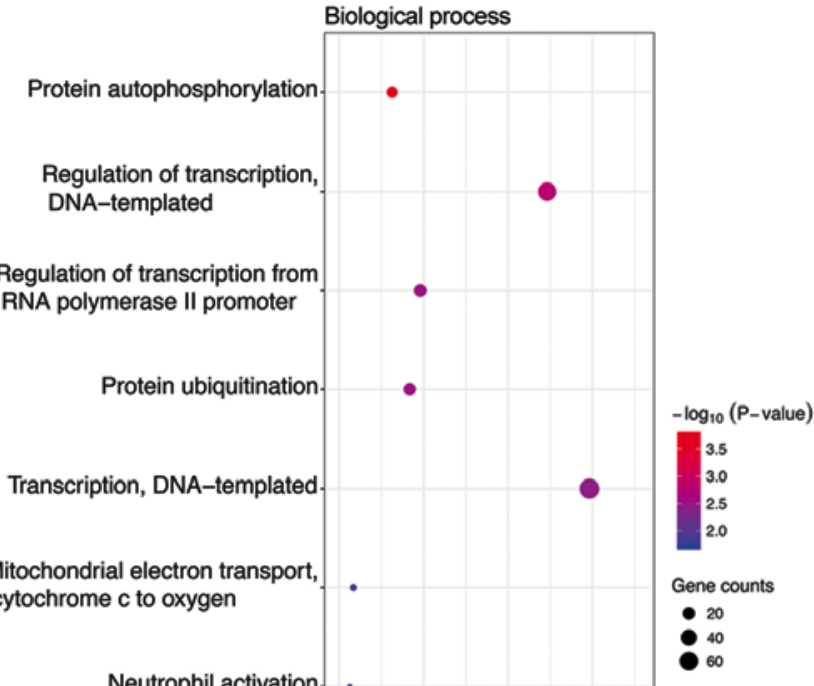

Wnt signaling pathway, calcium modulating pathway

Phospholipid biosynthetic process

Cell development.

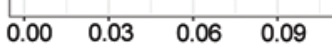

Figure 1. Gene Ontology (GO) functions for the target genes of the top 3 most highly upregulated miRNAs and the top 3 most highly downregulated miRNAs. (A) Enriched biological processes of the upregulated miRNAs; (B) enriched biological processes of the downregulated miRNAs.

A

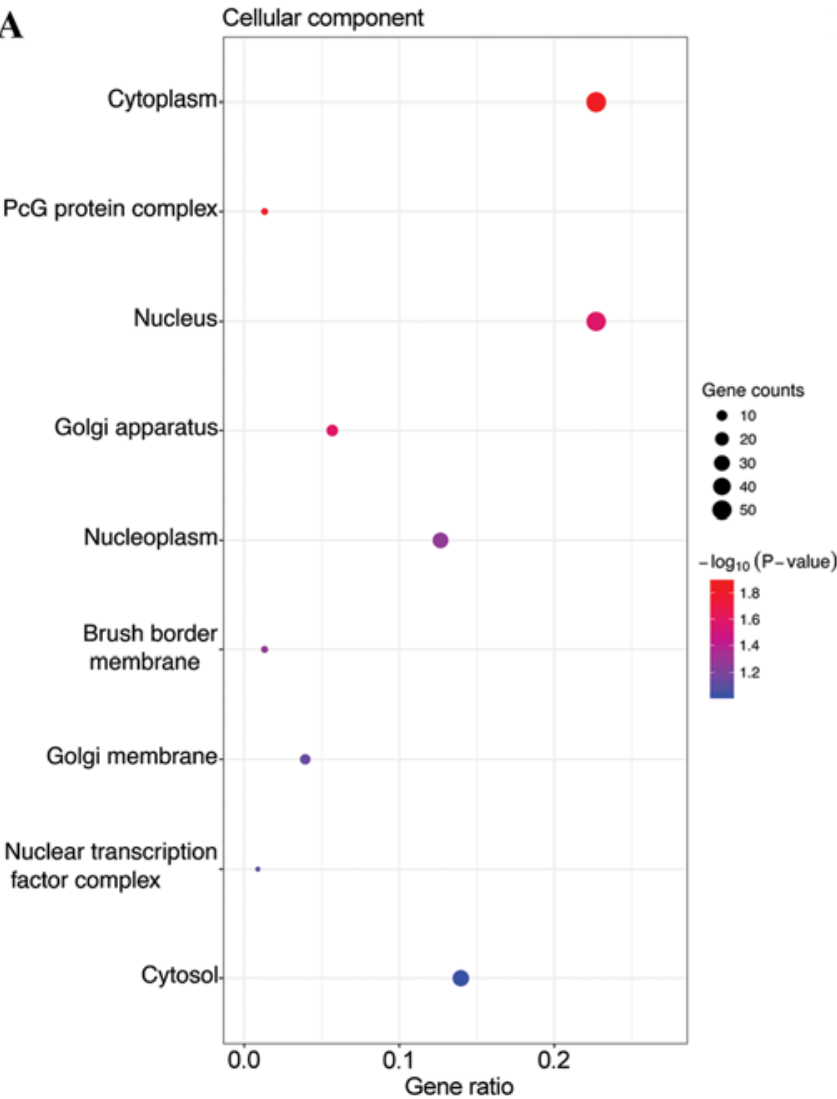

B

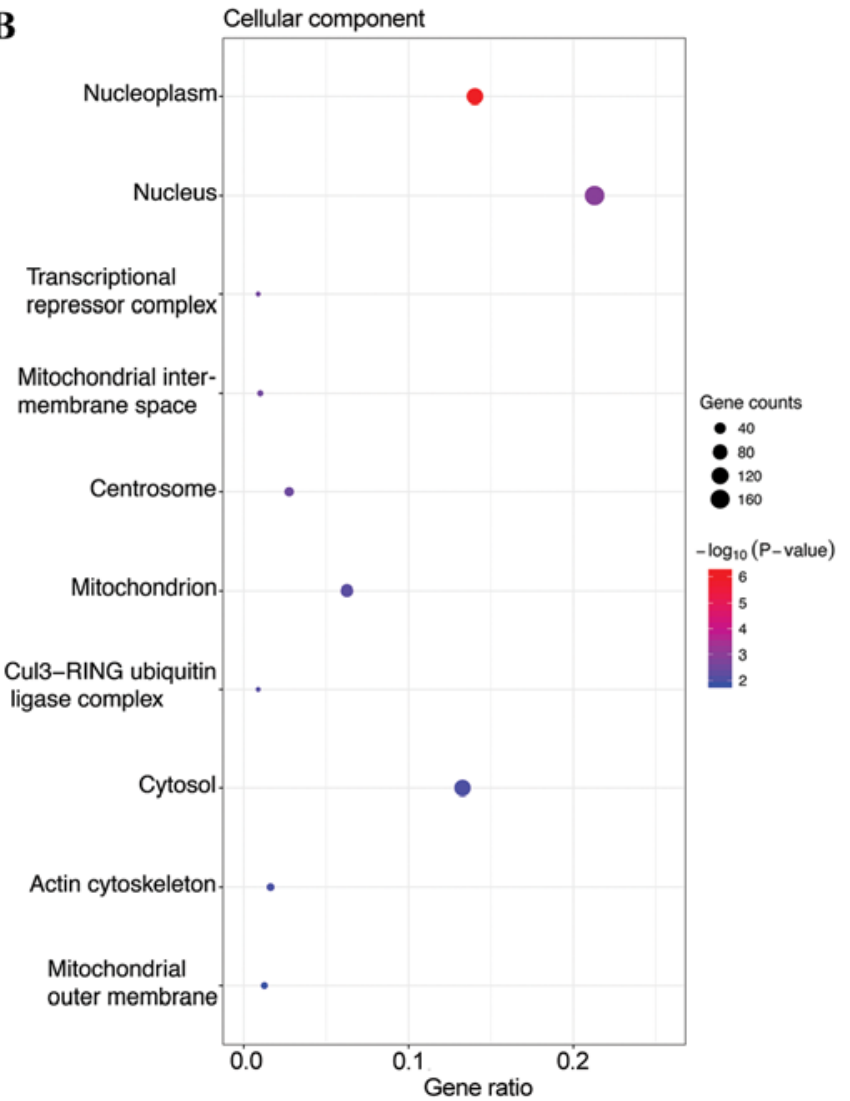

Figure 2. Gene Ontology (GO) functions for the target genes of the top 3 most highly upregulated miRNAs and the top 3 most highly downregulated miRNAs. (A) Enriched cellular components of the upregulated miRNAs; (B) enriched cellular components of the downregulated miRNAs. 

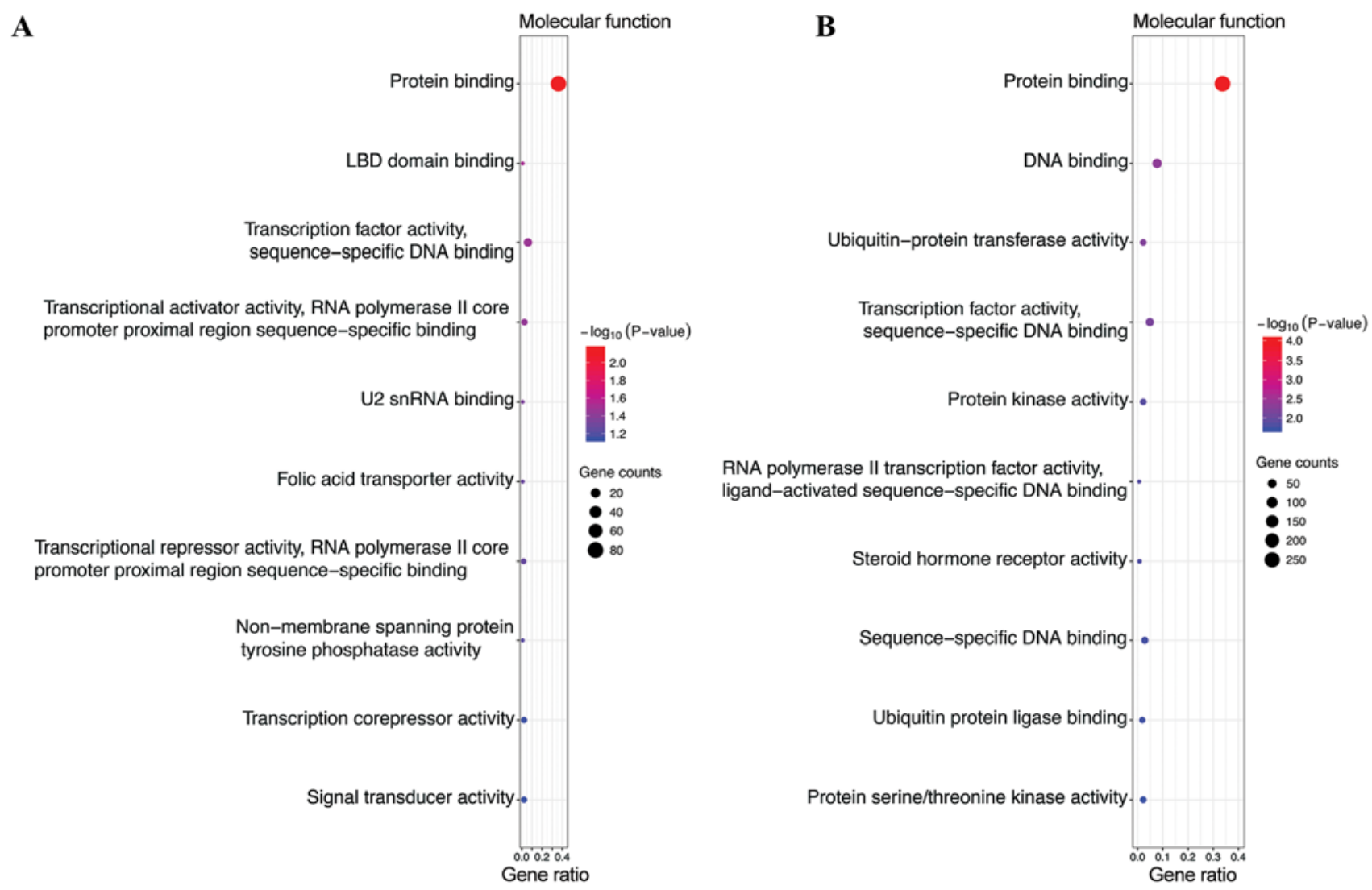

Figure 3. Gene Ontology (GO) functions for the target genes of the top 3 most highly upregulated miRNAs and the top 3 most highly downregulated miRNAs. (A) Enriched molecular functions of the upregulated miRNAs; (B) enriched molecular functions of the downregulated miRNAs.

A

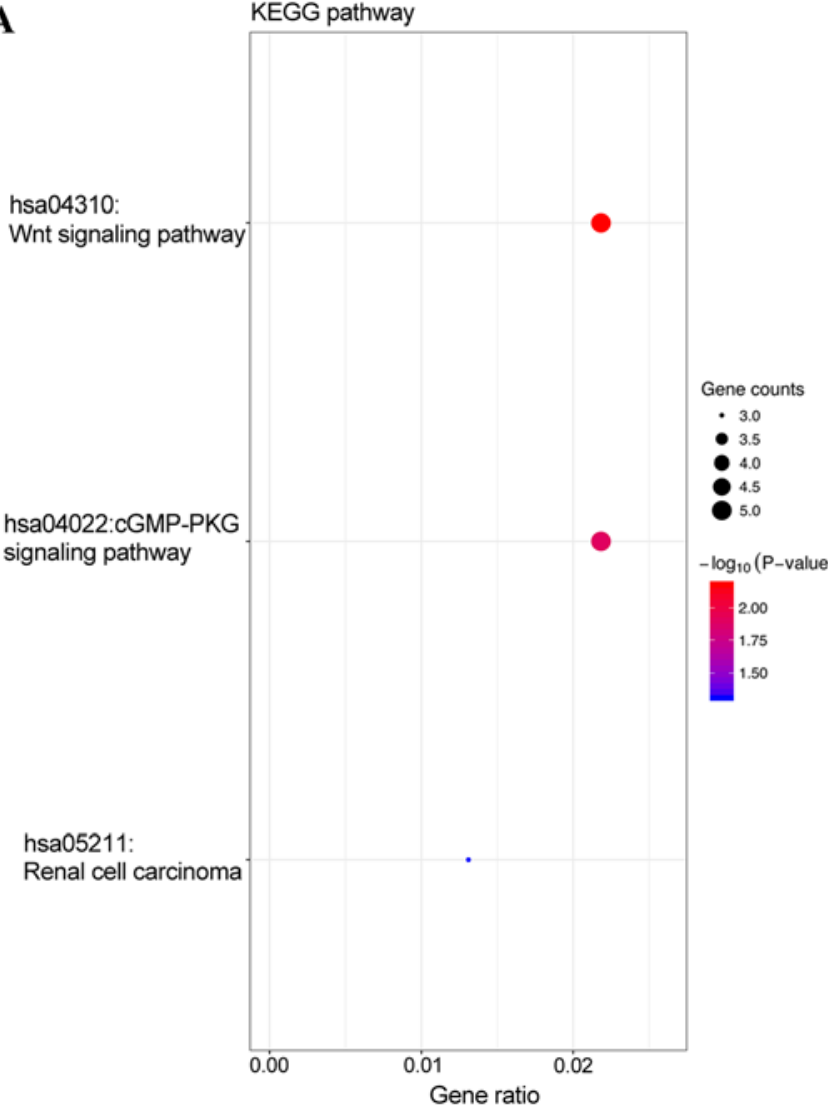

B

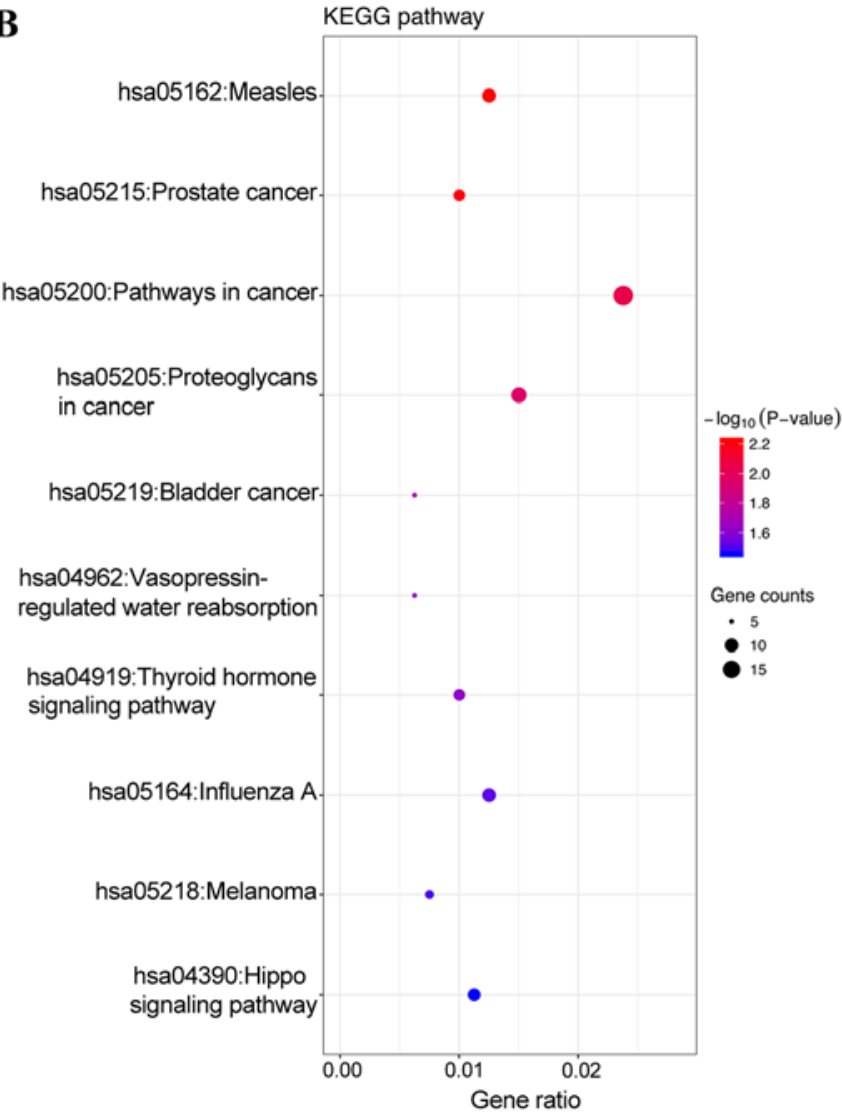

Figure 4. Kyoto Encyclopedia of Genes and Genomes (KEGG) pathways for the target genes of the top 3 most highly upregulated miRNAs and the top 3 most highly downregulated miRNAs. (A) Enriched KEGG pathways of the upregulated miRNAs; (B) enriched KEGG pathways of the downregulated miRNAs. 
A

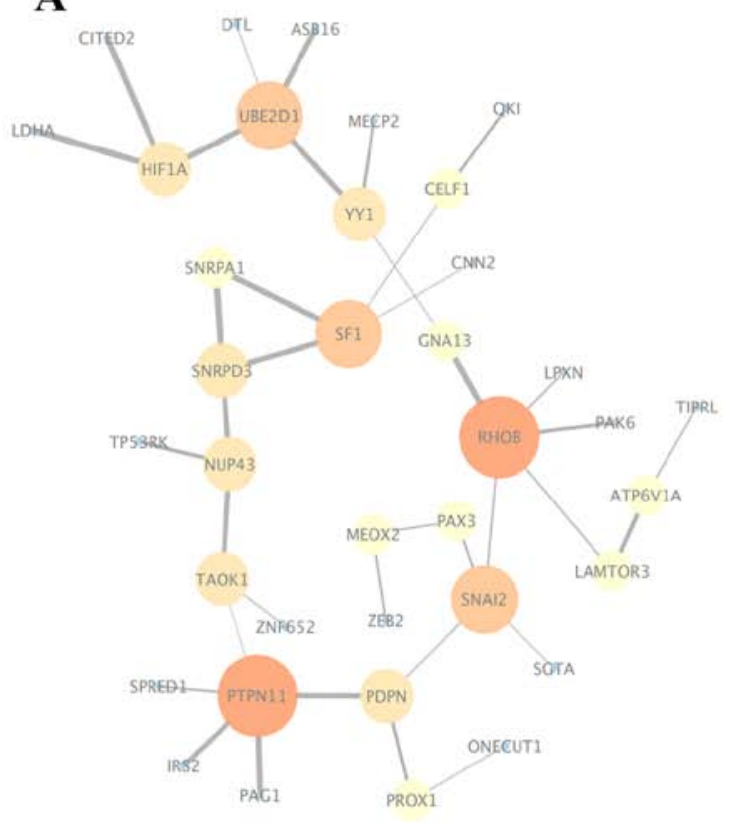

B

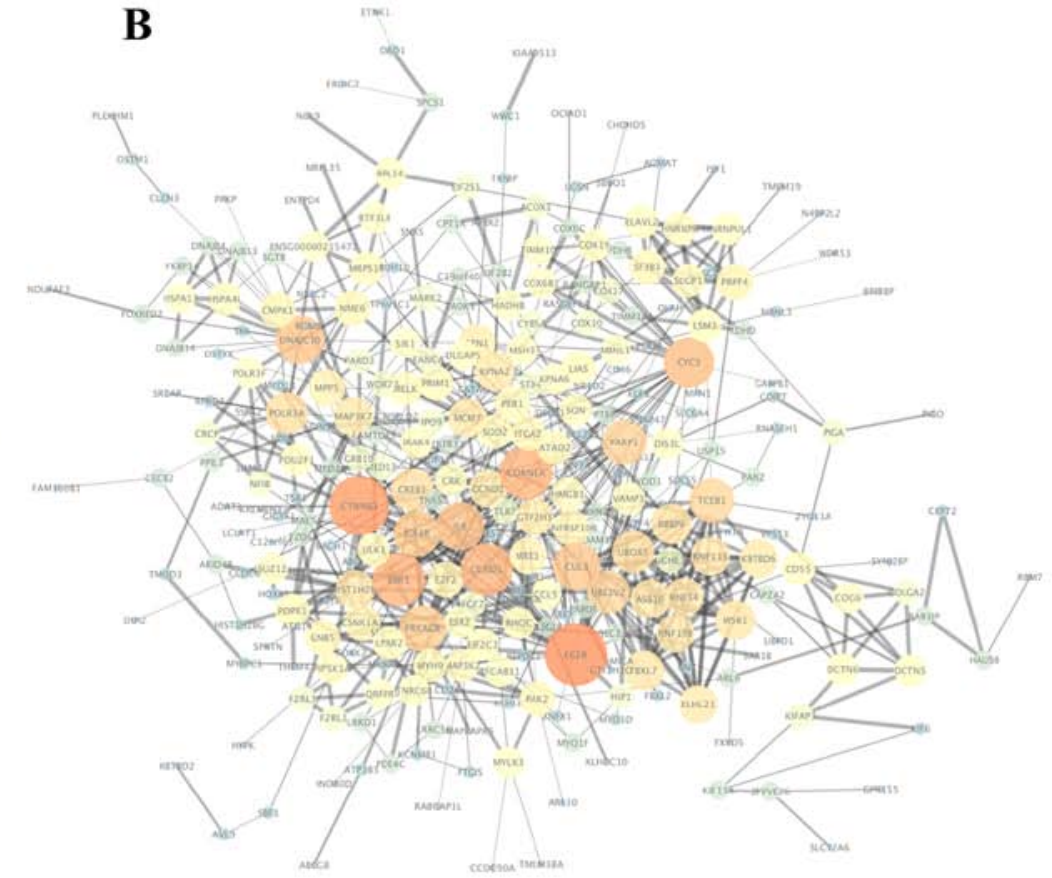

Figure 5. (A) Protein-protein interaction (PPI) network of the target genes of the top 3 most highly upregulated differentially expressed miRNAs (DEMs). (B) PPI network of the target genes of the top 3 most highly downregulated DEMs. Node size indicates the connectivity degree, and larger circles indicate a higher degree. Edge size indicates the combined scores between genes, which represent the confidence of protein interactions. The color gradually increases from dark (blue) to bright (red), representing the gradually increase in the number of interacting genes.

Subsequently, miRNA-hub gene networks were constructed by Cytoscape (Fig. 7). As shown in Fig. 7A, hsa-miR-489, the most highly upregulated DEM, potentially could target 9 (RHOB, PTPN11, SNAI2, UBE2D1, SF1, PDPN, NUP43, YY1 and HIF1A) of 10 hub genes. Five hub genes and 2 hub genes potentially were regulated by upregulated hsa-miR-138-1-3p and hsa-let-7d*, respectively. Additionally, according to Fig. 7B, hsa-miR-520b, the most highly downregulated DEM, potentially could also target 9 (EGFR, ESR $1, C D K N 1 A$, CCNDI, CYCS, DNAJC10, IL8, CUL3 and IGFIR) of $10 \mathrm{hub}$ genes. Three hub genes and 1 hub gene potentially were regulated by downregulated hsa-miR-875-5p and hsa-miR-671-3p, respectively. The results suggested that hsa-miR-489 and hsa-miR-520b may be the most important regulators of prolactin pituitary tumor aggressiveness.

\section{Discussion}

Prolactin-secreting pituitary adenoma is the most common (30-40\%) subtype of pituitary tumors and commonly presents with headache, visual disturbances, amenorrhea, galactorrhea, infertility and hyposexuality $(1,2)$. Most prolactinomas are noninvasive and easily treated by surgery, radiotherapy or medical treatment, including cabergoline and dopamine agonists, which are highly effective drugs for prolactinoma. However, aggressive prolactin pituitary tumors, with unknown incidence, are entities whose pathological behaviors lie between those of benign pituitary adenomas and malignant pituitary carcinomas. They display a rather distinct aggressive behavior with marked invasion of nearby anatomical structures, a tendency for resistance to conventional treatments and/or TMZ, and early postoperative recurrences $(3,4)$. Extensive research has been performed to explore potential biomarkers for early diagnosis and treatment of aggressive pituitary tumors. The Raf/MEK/ERK, PI3K/Akt/mTOR, and VEGFR pathways were found to be upregulated in pituitary tumors, suggesting that these pathways may be utilized to control pituitary tumor growth and progression (28-32). However, most targeted therapies based on the above pathways have been administered to patients with aggressive pituitary tumors without success (32-34). Therefore, further research is needed to discover aggressiveness-associated biomarkers with diagnostic and therapeutic value for aggressive prolactin pituitary tumors.

miRNAs are a group of small, endogenous noncoding RNAs that can repress protein expression by cleaving mRNA or inhibiting translation $(8,9)$. Mostly, miRNAs are recognized as having a significant role in the negative regulation of target gene expression, which contributes to tumorigenesis, invasion and metastasis in various types of tumors (10-12). Recent studies have shown that aberrant miRNA expression is involved in tumorigenesis and tumor development of pituitary adenomas, especially prolactin pituitary tumors (13-16). D'Angelo et al (35) found that miR-603, miR-34b, miR-548c-3p, miR-326, miR-570 and miR-432 were downregulated in prolactinomas, which can affect the G1-S transition process. Mussnich et al (36) found that miR-15, miR-26a, miR-196a-2, miR-16, Let-7a and miR-410 were downregulated in prolactinomas, which can negatively regulate pituitary cell proliferation. Roche et al (17) demonstrated that miR-183 was downregulated in aggressive prolactin tumors and inhibited tumor cell proliferation by directly targeting KIAA0101, which is involved in cell cycle activation and the inhibition of p53-p21-mediated cell cycle arrest. However, few studies, except for one reported by Roche et al (17) in 2015, have been 
Table IV. Functional roles of the hub genes of the top 3 upregulated/downregulated miRNAs identified in the PPI interaction.

\begin{tabular}{|c|c|c|c|}
\hline Gene symbol & Degree & Full name & Function \\
\hline \multicolumn{4}{|c|}{ Upregulated miRNAs } \\
\hline$R H O B$ & 16 & $\begin{array}{l}\text { Ras homolog family } \\
\text { member B }\end{array}$ & $\begin{array}{l}\text { Protein coding gene. Among its related pathways are ERK } \\
\text { signaling and focal adhesion. GO annotations related to this } \\
\text { gene include GTP binding and GDP binding. }\end{array}$ \\
\hline PTPN11 & 15 & $\begin{array}{l}\text { Protein tyrosine } \\
\text { phosphatase, } \\
\text { non-receptor } \\
\text { type } 11\end{array}$ & $\begin{array}{l}\text { Protein coding gene. Among its related pathways are immune } \\
\text { response Fce RI pathway and EGF/EGFR signaling pathway. } \\
\text { GO annotations related to this gene include protein domain- } \\
\text { specific binding and protein tyrosine phosphatase activity. }\end{array}$ \\
\hline SNAI2 & 15 & $\begin{array}{l}\text { Snail family } \\
\text { transcriptional } \\
\text { repressor } 2\end{array}$ & $\begin{array}{l}\text { Protein coding gene. Among its related pathways are ERK } \\
\text { signaling and adherens junction. GO annotations related to } \\
\text { this gene include sequence-specific DNA binding and tran } \\
\text { scriptional repressor activity, RNA polymerase II proximal } \\
\text { promoter sequence-specific DNA binding. }\end{array}$ \\
\hline$U B E 2 D 1$ & 14 & $\begin{array}{l}\text { Ubiquitin conjugating } \\
\text { enzyme E2 D1 }\end{array}$ & $\begin{array}{l}\text { Protein coding gene. Among its related pathways are gene } \\
\text { expression and cell cycle, mitotic. GO annotations related to } \\
\text { this gene include ligase activity and acid-amino acid ligase } \\
\text { activity. }\end{array}$ \\
\hline$S F 1$ & 14 & Splicing factor 1 & $\begin{array}{l}\text { Protein Coding gene. Among its related pathways are Oct } 4 \text { in } \\
\text { mammalian ESC pluripotency and mRNA splicing-major } \\
\text { pathway. GO annotations related to this gene include nucleic } \\
\text { acid binding and RNA binding. }\end{array}$ \\
\hline$P D P N$ & 14 & Podoplanin & $\begin{array}{l}\text { Protein coding gene. Among its related pathways are cytoskel } \\
\text { etal signaling and response to elevated platelet cytosolic } \mathrm{Ca}^{2+} \text {. } \\
\text { GO annotations related to this gene include amino acid trans } \\
\text { membrane transporter activity and folic acid transmembrane } \\
\text { transporter activity. }\end{array}$ \\
\hline NUP43 & 13 & Nucleoporin 43 & $\begin{array}{l}\text { Protein coding gene. Among its related pathways are cell } \\
\text { cycle, mitotic and transport of the SLBP independent mature } \\
\text { mRNA. }\end{array}$ \\
\hline$Y Y 1$ & 13 & $\begin{array}{l}\text { YY1 transcription } \\
\text { factor }\end{array}$ & $\begin{array}{l}\text { Protein coding gene. Among its related pathways are gene } \\
\text { expression and translational control. GO annotations related } \\
\text { to this gene include DNA binding transcription factor activity } \\
\text { and transcription coactivator activity. }\end{array}$ \\
\hline HIF $1 A$ & 11 & $\begin{array}{l}\text { Hypoxia inducible } \\
\text { factor } 1 \text { subunit } \alpha\end{array}$ & $\begin{array}{l}\text { Protein coding gene. Among its related pathways are ERK } \\
\text { signaling and central carbon metabolism in cancer. GO anno } \\
\text { tations related to this gene include DNA binding transcription } \\
\text { factor activity and protein heterodimerization activity. }\end{array}$ \\
\hline SNRPD3 & 11 & $\begin{array}{l}\text { Small nuclear ribonu } \\
\text { cleoprotein D3 } \\
\text { polypeptide }\end{array}$ & $\begin{array}{l}\text { Protein coding gene. Among its related pathways are mRNA } \\
\text { splicing-major pathway and processing of capped intronless } \\
\text { pre-mRNA. GO annotations related to this gene include } \\
\text { histone pre-mRNA DCP binding. }\end{array}$ \\
\hline
\end{tabular}

Downregulated miRNAs

EGFR

33 Epidermal growth factor receptor

CTNNB1

$31 \quad$ Catenin $\beta 1$
Protein coding gene. Among its related pathways are ERK signaling and gene expression. GO annotations related to this gene include identical protein binding and protein kinase activity.

Protein coding gene. Among its related pathways are ERK signaling and focal adhesion. GO annotations related to this gene include DNA binding transcription factor activity and binding.

Estrogen resistance and myocardial infarction. Among its related pathways are gene expression and integrated breast cancer pathway. GO annotations related to this gene include DNA binding transcription factor activity and identical protein binding. 
Table IV. Continued.

\begin{tabular}{|c|c|c|c|}
\hline Gene symbol & Degree & Full name & Function \\
\hline$C D K N 1 A$ & 25 & $\begin{array}{l}\text { Cyclin dependent } \\
\text { kinase inhibitor } 1 \mathrm{~A}\end{array}$ & $\begin{array}{l}\text { Protein coding gene. Among its related pathways are gene } \\
\text { expression and Akt signaling. GO annotations related to this } \\
\text { gene include ubiquitin protein ligase binding and cyclin } \\
\text { binding. }\end{array}$ \\
\hline$C C N D 1$ & 24 & Cyclin D1 & $\begin{array}{l}\text { Protein coding gene. Diseases associated with CCND1 } \\
\text { include myeloma, multiple and Von Hippel-Lindau syndrome. } \\
\text { Among its related pathways are ERK signaling and focal } \\
\text { adhesion. GO annotations related to this gene include protein } \\
\text { kinase activity and enzyme binding. }\end{array}$ \\
\hline$C Y C S$ & 23 & $\begin{array}{l}\text { Cytochrome } c \text {, } \\
\text { somatic }\end{array}$ & $\begin{array}{l}\text { Protein coding gene. Diseases associated with CYCS include } \\
\text { thrombocytopenia } 4 \text { and autosomal thrombocytopenia with } \\
\text { normal platelets. Among its related pathways are gene expres } \\
\text { sion and activation of caspases through apoptosome-mediated } \\
\text { cleavage. GO annotations related to this gene include iron ion } \\
\text { binding and electron transfer activity. }\end{array}$ \\
\hline DNAJC10 & 21 & $\begin{array}{l}\text { DNAJ heat shock } \\
\text { protein family } \\
(\text { Hsp40) member C10 }\end{array}$ & $\begin{array}{l}\text { Protein coding gene. Among its related pathways are protein } \\
\text { processing in endoplasmic reticulum. GO annotations related } \\
\text { to this gene include chaperone binding and protein disulfide } \\
\text { oxidoreductase activity. }\end{array}$ \\
\hline IL8 & 21 & $\begin{array}{l}\text { C-X-C motif } \\
\text { chemokine ligand } 8\end{array}$ & $\begin{array}{l}\text { Protein coding gene. Among its related pathways are Akt } \\
\text { signaling and rheumatoid arthritis. GO annotations related to } \\
\text { this gene include chemokine activity and interleukin- } 8 \\
\text { receptor binding. }\end{array}$ \\
\hline$C U L 3$ & 20 & Cullin 3 & $\begin{array}{l}\text { Protein Coding gene. Among its related pathways are RET } \\
\text { signaling and Class I MHC mediated antigen processing and } \\
\text { presentation. GO annotations related to this gene include } \\
\text { protein homodimerization activity and ubiquitin-protein trans } \\
\text { ferase activity. }\end{array}$ \\
\hline$I G F I R$ & 19 & $\begin{array}{l}\text { Insulin like growth } \\
\text { factor } 1 \text { receptor }\end{array}$ & $\begin{array}{l}\text { Protein coding gene. Among its related pathways are ERK } \\
\text { signaling and mTOR pathway. GO annotations related to this } \\
\text { gene include identical protein binding and protein kinase } \\
\text { activity. }\end{array}$ \\
\hline
\end{tabular}

PPI, protein-protein interaction; GO, Gene Ontology. Online database GeneCards (https://www.genecards.org).

performed to explore aggressiveness-associated miRNAs in aggressive prolactin pituitary tumors based on large-scale human tissue datasets. Additionally, based on the GSE46294 dataset, our study obtained different DEMs compared with those reported by Roche et al. The reasons may be due to different softwares or different algorithms when analyzing differentially expressed genes or RNAs, and due to the small sample size of the GSE46294 dataset (37).

In the present study, some aggressiveness-associated miRNAs were screened by performing a differential expression analysis based on an miRNA expression profile downloaded from the GEO database. The potential target genes of the top 3 most highly upregulated and most highly downregulated DEMs were collectively enriched for regulation of transcription from RNA polymerase II promoter, DNA-templated transcription, Wnt signaling pathway, protein binding, and transcription factor activity (sequence-specific DNA binding). Moreover, by constructing PPI networks, we identified the top 10 hub genes with the highest degree of connectivity with the top 3 most highly upregulated and downregulated DEMs. Hub genes of the upregulated DEMs were mainly enriched for proteoglycans in cancer, while hub genes of the downregulated DEMs were mainly enriched for proteoglycans in cancer, pathways in cancer, FoxO signaling pathway, and focal adhesion. Those pathways were all reported by previous studies to be associated with tumor growth, progression invasion and metastasis of various tumors (38-40). In our study, proteoglycan in cancer is the enriched pathway shared by both upregulated and downregulated DEMs. However, there is little research on proteoglycan in tumorigenesis, invasiveness and progression of pituitary tumors. Matano et al reported that endocan, a novel soluble dermatan sulfate proteoglycan, can function as a new invasion and angiogenesis marker of pituitary adenomas (40). More studies are needed to further research the functions of proteoglycan in pituitary adenomas, especially aggressive tumors.

Among the 20 hub genes, EGFR demonstrated the highest node degrees, suggesting that $E G F R$ was a key target associated 


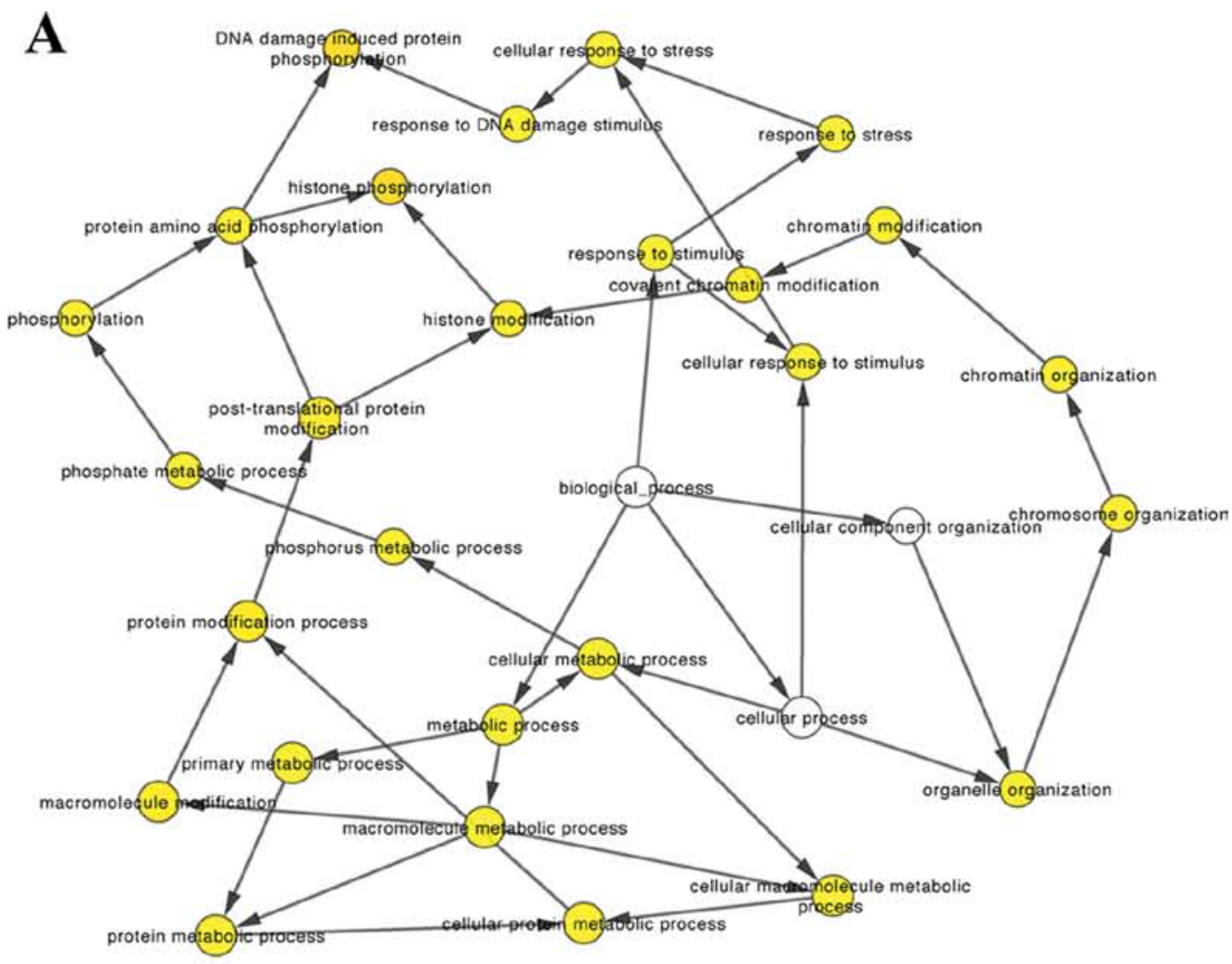

\section{B}

\section{Renal cell carcinoma_Homo sapiens_hsa05211}

Proteoglycans in cancer_Homo sapiens_hsa05205

mTOR signaling pathway_Homo sapiens_hsa04150

Epithelial cell signaling in Helicobacter pylori infection_Homo sapiens_hsa05120

Central carbon metabolism h cancer_Homo sapiens_hsa05230

Chronic myeloid leukema_Homo sapiens_hsa05220

Adipocytokine signaling pathway_Homo sapiens_hsa04920

Adherens junction_flomo sapiens_hsa04520

Choline metabolism in cancer_Homo sapiens_hsa05231

HIF-1 signaling pathway_Homo sapiens_hsa04066

\section{C}

Proteoglycans in cancer_Homo sapiens_hsa05205
Prostate cancer_Homo sapiens_hsa05215
Pathways in cancer_Homo sapiens_hsa05200
Glioma_Homo sapiens_hsa05214
Melanoma_Homo sapiens_hsa05218
FoxO signaling pathway_Homo_sapiens_hsa04068
Focal adhesion_Homo sapiens_hsa04510
Endometrial cancer_Homo sapiens_hsa05213
Bladder cancer_Homo sapiens_hsa05219
Colorectal cancer_Homo sapiens_hsa05210

Figure 6. (A) The biological process analysis of hub genes. Node color depth refers to the corrected ontology P-values. Node size indicates the number of genes involved in the ontologies. P $<0.01$ was considered statistically significant. (B) Enriched Kyoto Encyclopedia of Genes and Genomes (KEGG) pathways for the hub genes of the top 3 most highly upregulated miRNAs. (C) Enriched KEGG pathways for the hub genes of the top 3 most highly downregulated miRNAs. 
Table V. Functional and pathway enrichment analysis for the hub genes of the top 3 upregulated miRNAs.

\begin{tabular}{|c|c|c|c|}
\hline Category & Term & Pathway description & Genes \\
\hline \multicolumn{4}{|c|}{ Upregulated miRNAs } \\
\hline GO BP & GO:0032364 & Oxygen homeostasis & $H I F 1 A$ \\
\hline GO BP & GO:0032909 & Regulation of transforming growth factor $\beta 2$ production & $H I F 1 A$ \\
\hline GO BP & GO:0033483 & Gas homeostasis & HIF $1 A$ \\
\hline GO BP & GO:0032642 & Regulation of chemokine production & SNAI2, HIF 1A \\
\hline GO BP & GO:0046885 & Regulation of hormone biosynthetic process & HIF $1 A$ \\
\hline GO BP & GO:0043619 & $\begin{array}{l}\text { Regulation of transcription from RNA polymerase II } \\
\text { promoter in response to oxidative stress }\end{array}$ & HIF $1 A$ \\
\hline GO BP & GO:0070099 & Regulation of chemokine-mediated signaling pathway & $H I F 1 A$ \\
\hline GO BP & GO:0032352 & Positive regulation of hormone metabolic process & HIF $1 A$ \\
\hline GO BP & GO:0010839 & Negative regulation of keratinocyte proliferation & SNAI2 \\
\hline GO BP & GO:0071364 & Cellular response to epidermal growth factor stimulus & SNAI2, PTPN11 \\
\hline $\mathrm{GO} \mathrm{CC}$ & GO:0031528 & Microvillus membrane & $P D P N$ \\
\hline $\mathrm{GO} \mathrm{CC}$ & GO:0000243 & Commitment complex & SNRPD3 \\
\hline $\mathrm{GO} \mathrm{CC}$ & GO:0005683 & U7 snRNP & SNRPD3 \\
\hline $\mathrm{GO} \mathrm{CC}$ & GO:0005687 & U4 snRNP & SNRPD3 \\
\hline $\mathrm{GO} \mathrm{CC}$ & GO:0034709 & Methylosome & SNRPD3 \\
\hline $\mathrm{GO} \mathrm{CC}$ & GO:0031527 & Filopodium membrane & $P D P N$ \\
\hline $\mathrm{GO} \mathrm{CC}$ & GO:0071437 & Invadopodium & $P D P N$ \\
\hline $\mathrm{GO} \mathrm{CC}$ & GO:0031011 & Ino80 complex & $Y Y 1$ \\
\hline $\mathrm{GO} \mathrm{CC}$ & GO:0005685 & U1 snRNP & SNRPD3 \\
\hline $\mathrm{GO} \mathrm{CC}$ & GO:0031258 & Lamellipodium membrane & $P D P N$ \\
\hline GO MF & GO:0000400 & Four-way junction DNA binding & $Y Y 1$ \\
\hline GO MF & GO:0001227 & $\begin{array}{l}\text { Transcriptional repressor activity, RNA polymerase II } \\
\text { transcription regulatory region sequence-specific binding }\end{array}$ & $Y Y 1$, SNAI2 \\
\hline GO MF & GO:0019956 & Chemokine binding & $P D P N$ \\
\hline GO MF & GO:0043565 & Sequence-specific DNA binding & $\begin{array}{l}Y Y 1, \text { SNAI2, } \\
\text { HIF } 1 A\end{array}$ \\
\hline GO MF & GO:0061631 & Ubiquitin conjugating enzyme activity & $U B E 2 D 1$ \\
\hline GO MF & GO:0000217 & DNA secondary structure binding & $Y Y 1$ \\
\hline GO MF & GO:0061650 & Ubiquitin-like protein conjugating enzyme activity & $U B E 2 D 1$ \\
\hline GO MF & GO:0005158 & Insulin receptor binding & PTPN11 \\
\hline GO MF & GO:0035326 & Enhancer binding & $Y Y 1$ \\
\hline GO MF & GO:0001078 & $\begin{array}{l}\text { Transcriptional repressor activity, RNA polymerase II } \\
\text { core promoter proximal region sequence-specific binding }\end{array}$ & $Y Y 1, S N A I 2$ \\
\hline KEGG & hsa05211 & Renal cell carcinoma & PTPN11, HIF1A \\
\hline KEGG & hsa05205 & Proteoglycans in cancer & PTPN11, HIF1A \\
\hline KEGG & hsa04150 & mTOR signaling pathway & $H I F 1 A$ \\
\hline KEGG & hsa05120 & Epithelial cell signaling in Helicobacter pylori infection & PTPN11 \\
\hline KEGG & hsa05230 & Central carbon metabolism in cancer & $H I F 1 A$ \\
\hline KEGG & hsa05220 & Chronic myeloid leukemia & PTPN11 \\
\hline KEGG & hsa04920 & Adipocytokine signaling pathway & PTPN11 \\
\hline KEGG & hsa04520 & Adherens junction & SNAI2 \\
\hline KEGG & hsa05231 & Choline metabolism in cancer & $H I F 1 A$ \\
\hline KEGG & hsa04066 & HIF-1 signaling pathway & HIF $1 A$ \\
\hline
\end{tabular}

GO, Gene Ontology; BP, biological process; CC, cellular component; MF, molecular function; KEGG, Kyoto Encyclopedia of Genes and Genomes; hsa, Homo sapiens.

with the aggressiveness of prolactin pituitary tumors, which is consistent with previous studies $(4,41)$. EGFR encodes a transmembrane glycoprotein that is located on the cell surface and binds to epidermal growth factor (EGF). Binding 
Table VI. Functional and pathway enrichment analysis for the hub genes of top 3 downregulated miRNAs.

\begin{tabular}{|c|c|c|c|}
\hline Category & Term & Pathway description & Genes \\
\hline \multicolumn{4}{|c|}{ Downregulated miRNAs } \\
\hline GO BP & GO:0070141 & Response to UV-A & $C C N D 1, E G F R$ \\
\hline GO BP & GO:0097193 & Intrinsic apoptotic signaling pathway & CDKN1A, CUL3, DNAJC10, CYCS \\
\hline GO BP & GO:0032355 & Response to estradiol & CTNNB1, ESR1, EGFR \\
\hline GO BP & GO: 1903798 & $\begin{array}{l}\text { Regulation of production of miRNAs } \\
\text { involved in gene silencing by miRNA }\end{array}$ & ESR $1, E G F R$ \\
\hline GO BP & GO:0033674 & Positive regulation of kinase activity & CDKN1A, EGFR, IGFIR \\
\hline GO BP & GO:0001934 & $\begin{array}{l}\text { Positive regulation of protein } \\
\text { phosphorylation }\end{array}$ & $\begin{array}{l}C D K N 1 A, C C N D 1, E G F R, \\
I G F 1 R\end{array}$ \\
\hline GO BP & GO:0045737 & $\begin{array}{l}\text { Positive regulation of cyclin-dependent } \\
\text { protein serine/threonine kinase activity }\end{array}$ & $C C N D 1, E G F R$ \\
\hline GO BP & GO:0045740 & Positive regulation of DNA replication & $E G F R, I G F 1 R$ \\
\hline GO BP & GO:0006367 & $\begin{array}{l}\text { Transcription initiation from RNA } \\
\text { polymerase II promoter }\end{array}$ & CDKN1A, CCND1, ESR1 \\
\hline GO BP & GO:0034333 & Adherens junction assembly & $C T N N B 1$ \\
\hline $\mathrm{GO} \mathrm{CC}$ & GO:0030128 & Clathrin coat of endocytic vesicle & $E G F R$ \\
\hline $\mathrm{GO} \mathrm{CC}$ & GO:0030122 & AP-2 adaptor complex & EGFR \\
\hline $\mathrm{GO} \mathrm{CC}$ & GO:0030131 & Clathrin adaptor complex & $E G F R$ \\
\hline $\mathrm{GO} \mathrm{CC}$ & GO:1990907 & $\beta$-catenin-TCF complex & CTNNB1 \\
\hline $\mathrm{GO} \mathrm{CC}$ & GO:0005719 & Nuclear euchromatin & CTNNB1 \\
\hline GO CC & GO:0000791 & Euchromatin & $C T N N B 1$ \\
\hline $\mathrm{GO} \mathrm{CC}$ & GO:0035327 & Transcriptionally active chromatin & ESR1 \\
\hline $\mathrm{GO} \mathrm{CC}$ & GO:0000790 & Nuclear chromatin & CTNNB1, ESRl \\
\hline $\mathrm{GO} \mathrm{CC}$ & GO:0005758 & Mitochondrial intermembrane space & CYCS \\
\hline $\mathrm{GO} \mathrm{CC}$ & GO:0016342 & Catenin complex & CTNNB1 \\
\hline GO MF & GO:0097472 & $\begin{array}{l}\text { Cyclin-dependent protein kinase } \\
\text { activity }\end{array}$ & $C D K N 1 A, C C N D 1$ \\
\hline GO MF & GO:0019900 & Kinase binding & CDKN1A, CCND1, CTNNB1, ESR1 \\
\hline GO MF & GO:0004693 & $\begin{array}{l}\text { Cyclin-dependent protein serine/ } \\
\text { threonine kinase activity }\end{array}$ & $C D K N 1 A, C C N D 1$ \\
\hline GO MF & GO:0004709 & MAP kinase kinase kinase activity & $E G F R, I G F 1 R$ \\
\hline GO MF & GO:0001223 & Transcription coactivator binding & ESRl \\
\hline GO MF & GO:0044389 & Ubiquitin-like protein ligase binding & CDKN1A, CUL3, EGFR \\
\hline GO MF & GO:0019901 & Protein kinase binding & $\begin{array}{l}C D K N 1 A, C C N D 1, E S R 1, E G F R, \\
I G F 1 R\end{array}$ \\
\hline GO MF & GO:0030331 & Estrogen receptor binding & CTNNB1, ESR1 \\
\hline GO MF & GO:0016671 & $\begin{array}{l}\text { Oxidoreductase activity, acting on a } \\
\text { sulfur group of donors, disulfide as } \\
\text { acceptor }\end{array}$ & DNAJC 10 \\
\hline GO MF & GO:0046934 & $\begin{array}{l}\text { Phosphatidylinositol-4,5-bisphosphate } \\
\text { 3-kinase activity }\end{array}$ & ESRl, EGFR \\
\hline KEGG & hsa05205 & Proteoglycans in cancer & $\begin{array}{l}C D K N 1 A, C C N D 1, E S R 1, C T N N B 1, \\
E G F R, I G F 1 R\end{array}$ \\
\hline KEGG & hsa05215 & Prostate cancer & $\begin{array}{l}C D K N 1 A, C C N D 1, C T N N B 1 \\
E G F R, I G F 1 R\end{array}$ \\
\hline KEGG & hsa05200 & Pathways in cancer & $\begin{array}{l}C D K N 1 A, C C N D 1, C T N N B 1 \\
C Y C S, E G F R, I G F 1 R\end{array}$ \\
\hline KEGG & hsa05214 & Glioma & $C D K N 1 A, C C N D 1, E G F R, I G F 1 R$ \\
\hline KEGG & hsa05218 & Melanoma & $C D K N 1 A, C C N D 1, E G F R, I G F 1 R$ \\
\hline KEGG & hsa04068 & FoxO signaling pathway & $C D K N 1 A, C C N D 1, E G F R, I G F 1 R$ \\
\hline KEGG & hsa04510 & Focal adhesion & $C C N D 1, C T N N B 1, E G F R, I G F 1 R$ \\
\hline
\end{tabular}


Table VI. Continued.

\begin{tabular}{llll}
\hline Category & Term & Pathway description & \multicolumn{1}{c}{ Genes } \\
\hline KEGG & hsa05213 & Endometrial cancer & CCND1, CTNNB1, EGFR \\
KEGG & hsa05219 & Bladder cancer & CDKN1A, CCND1, EGFR \\
KEGG & hsa05210 & Colorectal cancer & CCND1, CYCS, CTNNB1 \\
\hline
\end{tabular}

GO, Gene Ontology; BP, biological process; CC, cellular component; MF, molecular function; KEGG, Kyoto Encyclopedia of Genes and Genomes; hsa, Homo sapiens.
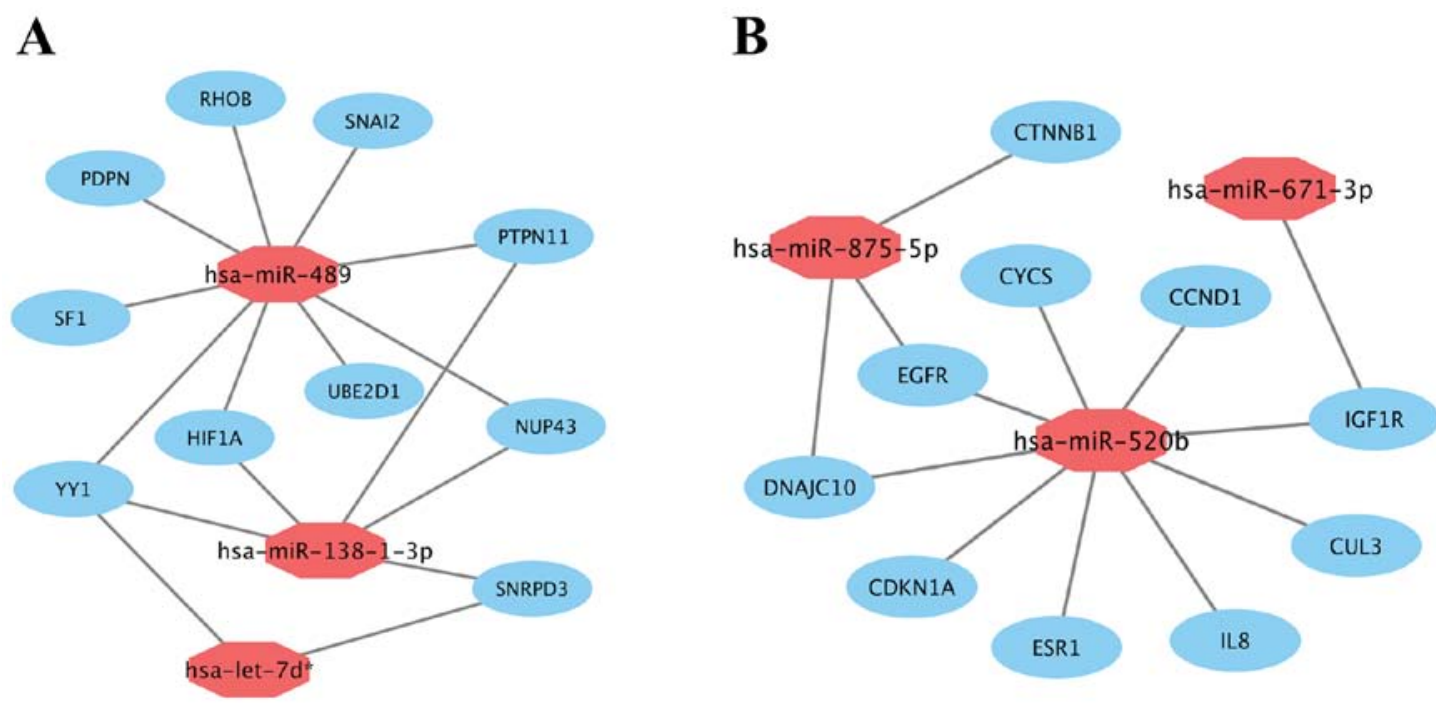

Figure 7. miRNA-hub gene network (A) for the top 3 most highly upregulated miRNAs and their hub genes; (B) for the top 3 most highly downregulated miRNAs and their hub genes.

of the protein to a ligand induces receptor dimerization and tyrosine autophosphorylation, leading to cell proliferation. $E G F R$ involvement in the tumorigenesis and invasion of pituitary tumors, especially aggressive prolactinomas, has been reported by previous studies, and mutations in this gene can be utilized as potential targets in the treatment of aggressive prolactinomas. As reported in the literature, tyrosine kinase inhibitors (TKIs), such as lapatanib, sunitinib and erlotinib, have been trialed as first- or second-line treatments based on the VEGFR pathway, but most of them have failed $(4,29-32,34)$. In addition, in the present study, we found that EGFR may be negatively modulated by hsa-miR-520b using the miRTarBase database; furthermore, hsa-miR-520b can be regulated by $E G F R$ due to its association with the biological process regulation of production of miRNAs involved in gene silencing by miRNA (30-32). This interesting finding may allow the use of this potential pathway for the diagnosis or treatment of aggressive prolactinomas in the future.

Subsequently, by constructing an miRNA-hub gene network, we found that most hub genes were potentially modulated by hsa-miR-489 and hsa-miR-520b, suggesting that these miRNAs may be the most important regulators of prolactin pituitary tumor aggressiveness. Recent studies demonstrated that hsa-miR-489 acts as a tumor suppressor in hepatocellular carcinoma (42), gastric cancer (43), breast cancer (44), glioma (45), hypopharyngeal squamous cell carcinoma (46), bladder cancer (47) and colorectal cancer (48). Downregulation of miR-489 was reported to be associated with the tumorigenesis, invasion, and metastasis of various tumors, suggesting an important role for hsa-miR-489 in predicting prognosis and acting as a drug target. However, the roles of hsa-miR-489 in pituitary tumors, especially aggressive prolactinomas, have not been previously studied. Additionally, hsa-miR-520b was reported to have a suppressive effect on tumor cell proliferation, migration, invasion and epithelial-to-mesenchymal transition (EMT) in colorectal cancer (49), glioblastoma (50), hepatoma (51), head-neck cancer (52), breast cancer (53), lung cancer (54) and gastric cancer (55). Expression of hsa-miR-520b is lower in tumor tissues than in normal tissues, significantly promoting the proliferation, migration, and invasion of tumor cells. Unlike other tumors, Liang et al (56) reported that hsa-miR-520b was upregulated in nonfunctioning and gonadotropin-secreting pituitary adenomas relative to normal pituitaries, which indicated that miR-520b functions as a tumor inducer in benign pituitary adenoma (56). However, whether hsa-miR-520b acts as a promoter or suppressor in aggressive prolactin pituitary tumors has not been previously studied. According to our study, we speculate that upregulation of hsa-miR-489 suppresses aggressiveness and progression, while downregulation of hsa-miR-520b promotes the aggressiveness and progression of aggressive prolactinomas. Such ambivalent miRNA expression might be one of the reasons 
that aggressive prolactin pituitary tumors lie on the spectrum between 'benign' pituitary adenomas and 'malignant' pituitary carcinomas. It will be extremely meaningful to authenticate the functions of hsa-miR-489 and hsa-miR-520b and elucidate the mechanisms by which they regulate aggressive behaviors, resistance to treatments and early recurrence in aggressive prolactin pituitary tumors.

There are some limitations of the present study. First, the sample size of GSE46294 is rather small (only 12 samples), which may cause some bias when identifying the differentially expressed miRNAs. Second, the expression of the differentially expressed miRNAs was not validated by RT-qPCR analysis with our clinical pituitary samples. Further studies are needed to experimentally verify the results of this study.

In conclusion, we successfully identified one key target gene, EGFR, and two crucial miRNAs, hsa-miR-489 and hsa-miR-520b, associated with aggressiveness based on bioinformatic analysis. These findings may provide potential candidate biomarkers for the early diagnosis and individualized treatment of aggressive prolactin pituitary tumors. However, further research is needed to experimentally verify the results of this study.

\section{Acknowledgements}

Not applicable.

\section{Funding}

Not applicable.

\section{Availability of data and materials}

The GSE46294 datasets analyzed during the present study are available in the GEO repository (http://www.ncbi.nlm. nih.gov/geo/). The potential target genes of DEMs were predicted by miRTarBase (http://mirtarbase.mbc.nctu.edu. tw/). The DAVID database (http://david.ncifcrf.gov/) was used to perform functional annotation and pathway enrichment analysis for genes. The STRING database (http://string-db. org) was used to assess functional associations among genes.

\section{Authors' contributions}

All authors conceived and designed the study. LG, XG and CF performed data curation and analysis. KD and WL analyzed and interpreted the results. ZW and BX drafted and reviewed the manuscript. All authors read and approved the final manuscript.

\section{Ethics approval and consent to participate}

Not applicable.

\section{Patient consent for publication}

Not applicable.

\section{Competing interests}

The authors declare that they have no competing interests.

\section{References}

1. Kaltsas GA, Nomikos P, Kontogeorgos G, Buchfelder M and Grossman AB: Clinical review: Diagnosis and management of pituitary carcinomas. J Clin Endocrinol Metab 90: 3089-3099, 2005.

2. Fernandez A, Karavitaki N and Wass JA: Prevalence of pituitary adenomas: A community-based, cross-sectional study in Banbury (Oxfordshire, UK). Clin Endocrinol (Oxf) 72: 377-382, 2010.

3. Dai C, Feng M, Liu X, Ma S, Sun B, Bao X, Yao Y, Deng K, Wang Y, Xing B, et al: Refractory pituitary adenoma: A novel classification for pituitary tumors. Oncotarget 7: 83657-83668, 2016.

4. Raverot G, Burman P, McCormack A, Heaney A, Petersenn S, Popovic V, Trouillas J and Dekkers OM; European Society of Endocrinology: European society of endocrinology clinical practice guidelines for the management of aggressive pituitary tumours and carcinomas. Eur J Endocrinol 178: G1-G24, 2018.

5. Heaney A: Management of aggressive pituitary adenomas and pituitary carcinomas. J Neurooncol 117: 459-468, 2014.

6. Lasolle H, Cortet C, Castinetti F, Cloix L, Caron P, Delemer B, Desailloud R, Jublanc C, Lebrun-Frenay C, Sadoul JL, et al: Temozolomide treatment can improve overall survival in aggressive pituitary tumors and pituitary carcinomas. Eur J Endocrinol 176: 769-777, 2017.

7. Losa M, Bogazzi F, Cannavo S, Ceccato F, Curtò L, De Marinis L. Iacovazzo D, Lombardi G, Mantovani G, Mazza E, et al: Temozolomide therapy in patients with aggressive pituitary adenomas or carcinomas. J Neurooncol 126: 519-525, 2016.

8. Shukla GC, Singh J and Barik S: MicroRNAs: Processing, maturation, target recognition and regulatory functions. Mol Cell Pharmacol 3: 83-92, 2011.

9. Treiber T, Treiber N and Meister G: Regulation of microRNA biogenesis and its crosstalk with other cellular pathways. Nat Rev Mol Cell Biol 20: 5-20, 2019.

10. Croce CM and Calin GA: miRNAs, cancer, and stem cell division. Cell 122: 6-7, 2005.

11. Berindan-Neagoe I, Monroig Pdel C, Pasculli B and Calin GA: MicroRNAome genome: A treasure for cancer diagnosis and therapy. CA Cancer J Clin 64: 311-336, 2014.

12. Lu J, Getz G, Miska EA, Alvarez-Saavedra E, Lamb J, Peck D, Sweet-Cordero A, Ebert BL, Mak RH, Ferrando AA, et al: MicroRNA expression profiles classify human cancers. Nature 435: 834-838, 2005.

13. Feng Y, Mao ZG, Wang X, Du Q, Jian M, Zhu D, Xiao Z, Wang HJ and Zhu YH: MicroRNAs and target genes in pituitary adenomas. Horm Metab Res 50: 179-192, 2018.

14. Di Ieva A, Butz H, Niamah M, Rotondo F, De Rosa S, Sav A, Yousef GM, Kovacs K and Cusimano MD: MicroRNAs as biomarkers in pituitary tumors. Neurosurgery 75: 181-189; discussion 188-189, 2014.

15. Zhang QJ and Xu C: The role of microRNAs in the pathogenesis of pituitary tumors. Front Biosci (Landmark Ed) 21: 1-7, 2016.

16. Wei Z, Zhou C, Liu M, Yao Y, Sun J, Xiao J, Ma W, Zhu H and Wang R: MicroRNA involvement in a metastatic non-functioning pituitary carcinoma. Pituitary 18: 710-721, 2015.

17. Roche M, Wierinckx A, Croze S, Rey C, Legras-Lachuer C, Morel AP, Fusco A, Raverot G, Trouillas J and Lachuer J: Deregulation of miR-183 and KIAA0101 in aggressive and malignant pituitary tumors. Front Med (Lausanne) 2: 54, 2015.

18. Edgar R, Domrachev M and Lash AE: Gene expression omnibus: NCBI gene expression and hybridization array data repository. Nucleic Acids Res 30: 207-210, 2002.

19. Barrett T, Wilhite SE, Ledoux P, Evangelista C, Kim IF, Tomashevsky M, Marshall KA, Phillippy KH, Sherman PM, Holko M, et al: NCBI GEO: Archive for functional genomics data sets-update. Nucleic Acids Res 41 (Database Issue): D991-D995, 2013.

20. Chou CH, Shrestha S, Yang CD, Chang NW, Lin YL, Liao KW, Huang WC, Sun TH, Tu SJ, Lee WH, et al: miRTarBase update 2018: A resource for experimentally validated microRNA-target interactions. Nucleic Acids Res 46D: D296-D302, 2018.

21. Huang da W, Sherman BT and Lempicki RA: Systematic and integrative analysis of large gene lists using DAVID bioinformatics resources. Nat Protoc 4: 44-57, 2009.

22. Kanehisa M, Furumichi M, Tanabe M, Sato Y and Morishima K: KEGG: New perspectives on genomes, pathways, diseases and drugs. Nucleic Acids Res 45D: D353-D361, 2017. 
23. Ashburner M, Ball CA, Blake JA, Botstein D, Butler $\mathrm{H}$, Cherry JM, Davis AP, Dolinski K, Dwight SS, Eppig JT, et al: Gene ontology: Tool for the unification of biology. The gene ontology consortium. Nat Genet 25: 25-29, 2000 .

24. von Mering C, Huynen M, Jaeggi D, Schmidt S, Bork P and Snel B: STRING: A database of predicted functional associations between proteins. Nucleic Acids Res 31: 258-261, 2003.

25. Shannon P, Markiel A, Ozier O, Baliga NS, Wang JT, Ramage D, Amin N, Schwikowski B and Ideker T: Cytoscape: A software environment for integrated models of biomolecular interaction networks. Genome Res 13: 2498-2504, 2003.

26. Bandettini WP, Kellman P, Mancini C, Booker OJ, Vasu S, Leung SW, Wilson JR, Shanbhag SM, Chen MY and Arai AE: MultiContrast delayed enhancement (MCODE) improves detection of subendocardial myocardial infarction by late gadolinium enhancement cardiovascular magnetic resonance: A clinical validation study. J Cardiovasc Magn Reson 14: 83, 2012

27. Maere S, Heymans K and Kuiper M: BiNGO: A cytoscape plugin to assess overrepresentation of gene ontology categories in biological networks. Bioinformatics 21: 3448-3449, 2005.

28. Dworakowska D and Grossman AB: The pathophysiology of pituitary adenomas. Best Pract Res Clin Endocrinol Metab 23: 525-541, 2009

29. Fukuoka H, Cooper O, Ben-Shlomo A, Mamelak A, Ren SG, Bruyette D and Melmed S: EGFR as a therapeutic target for human, canine, and mouse ACTH-secreting pituitary adenomas. J Clin Invest 121: 4712-4721, 2011.

30. Fukuoka H, Cooper O, Mizutani J, Tong Y, Ren SG, Bannykh S and Melmed S: HER2/ErbB2 receptor signaling in rat and human prolactinoma cells: Strategy for targeted prolactinoma therapy. Mol Endocrinol 25: 92-103, 2011.

31. Vlotides G, Siegel E, Donangelo I, Gutman S, Ren SG and Melmed S: Rat prolactinoma cell growth regulation by epidermal growth factor receptor ligands. Cancer Res 68: 6377-6386, 2008

32. Cooper O, Mamelak A, Bannykh S, Carmichael J, Bonert V, Lim S, Cook-Wiens G and Ben-Shlomo A: Prolactinoma ErbB receptor expression and targeted therapy for aggressive tumors. Endocrine 46: 318-327, 2014.

33. Donovan LE, Arnal AV, Wang SH and Odia Y: Widely metastatic atypical pituitary adenoma with mTOR pathway STK11(F298L) mutation treated with everolimus therapy. CNS Oncol 5: 203-209, 2016.

34. Ortiz LD, Syro LV, Scheithauer BW, Ersen A, Uribe H, Fadul CE, Rotondo F, Horvath E and Kovacs K: Anti-VEGF therapy in pituitary carcinoma. Pituitary 15: 445-449, 2012

35. D'Angelo D, Palmieri D, Mussnich P, Roche M, Wierinckx A, Raverot G, Fedele M, Croce CM, Trouillas J and Fusco A: Altered microRNA expression profile in human pituitary GH adenomas: Down-regulation of miRNA targeting HMGA1, HMGA2, and E2F1. J Clin Endocrinol Metab 97: E1128-E1138, 2012.

36. Mussnich P, Raverot G, Jaffrain-Rea ML, Fraggetta F, Wierinckx A, Trouillas J, Fusco A and D'Angelo D: Downregulation of miR-410 targeting the cyclin B1 gene plays a role in pituitary gonadotroph tumors. Cell Cycle 14: 2590-2597, 2015.

37. Finotello F and Di Camillo B: Measuring differential gene expression with RNA-seq: Challenges and strategies for data analysis. Brief Funct Genomics 14: 130-142, 2015

38. Farhan M, Wang H, Gaur U, Little PJ, Xu J and Zheng W: FOXO signaling pathways as therapeutic targets in cancer. Int J Biol Sci 13: 815-827, 2017.

39. Xu F, Zhang J, Hu G, Liu L and Liang W: Hypoxia and TGF- $\beta 1$ induced PLOD2 expression improve the migration and invasion of cervical cancer cells by promoting epithelial-to-mesenchymal transition (EMT) and focal adhesion formation. Cancer Cell Int 17: 54, 2017.
40. Matano F, Yoshida D, Ishii Y, Tahara S, Teramoto A and Morita A: Endocan, a new invasion and angiogenesis marker of pituitary adenomas. J Neurooncol 117: 485-491, 2014

41. Cooper O, Vlotides G, Fukuoka H, Greene MI and Melmed S: Expression and function of ErbB receptors and ligands in the pituitary. Endocr Relat Cancer 18: R197-R211, 2011.

42. Lin Y, Liu J, Huang Y, Liu D, Zhang G and Kan H: microRNA-489 plays an anti-metastatic role in human hepatocellular carcinoma by targeting matrix metalloproteinase-7. Transl Oncol 10: 211-220, 2017.

43. Zhang B, Ji S, Ma F, Ma Q, Lu X and Chen X: miR-489 acts as a tumor suppressor in human gastric cancer by targeting PROX1. Am J Cancer Res 6: 2021-2030, 2016.

44. Chai P, Tian J, Zhao D, Zhang H, Cui J, Ding K and Liu B: GSE1 negative regulation by miR-489-5p promotes breast cancer cell proliferation and invasion. Biochem Biophys Res Commun 471: $123-128,2016$.

45. Xu D, Liu R, Meng L, Zhang Y, Lu G and Ma P: Long non-coding RNA ENST01108 promotes carcinogenesis of glioma by acting as a molecular sponge to modulate miR-489. Biomed Pharmacother 100: 20-28, 2018.

46. Kikkawa N, Hanazawa T, Fujimura L, Nohata N, Suzuki H, Chazono H, Sakurai D, Horiguchi S, Okamoto Y and Seki N: miR-489 is a tumour-suppressive miRNA target PTPN11 in hypopharyngeal squamous cell carcinoma (HSCC). Br J Cancer 103: 877-884, 2010.

47. Li J, Qu W, Jiang Y, Sun Y, Cheng Y, Zou T and Du S: miR-489 suppresses proliferation and invasion of human bladder cancer cells. Oncol Res 24: 391-398, 2016.

48. Gao S, Liu H, Hou S, Wu L, Yang Z, Shen J, Zhou L, Zheng SS and Jiang B: miR-489 suppresses tumor growth and invasion by targeting HDAC7 in colorectal cancer. Clin Transl Oncol 20: 703-712, 2018 .

49. Xiao J, Li G, Zhou J, Wang S, Liu D, Shu G, Zhou J and Ren F: MicroRNA-520b functions as a tumor suppressor in colorectal cancer by inhibiting defective in cullin neddylation 1 domain containing 1 (DCUN1D1). Oncol Res 26: 593-604, 2018.

50. Liu X, Wang F, Tian L, Wang T, Zhang W, Li B and Bai YA: MicroRNA-520b affects the proliferation of human glioblastoma cells by directly targeting cyclin D1. Tumour Biol 37: 7921-7928, 2016.

51. Zhang W, Kong G, Zhang J, Wang T, Ye L and Zhang X: MicroRNA-520b inhibits growth of hepatoma cells by targeting MEKK2 and cyclin D1. PLoS One 7: e31450, 2012

52. Lu YC, Cheng AJ, Lee LY, You GR, Li YL, Chen HY and Chang JT: miR-520b as a novel molecular target for suppressing stemness phenotype of head-neck cancer by inhibiting CD44. Sci Rep 7: 2042, 2017.

53. Hu N, Zhang J, Cui W, Kong G, Zhang S, Yue L, Bai X, Zhang Z, Zhang $\mathrm{W}$, Zhang $\mathrm{X}$ and Ye L: miR-520b regulates migration of breast cancer cells by targeting hepatitis $\mathrm{B} \mathrm{X}$-interacting protein and interleukin-8. J Biol Chem 286: 13714-13722, 2011.

54. Jin K, Zhao W, Xie X, Pan Y, Wang K and Zhang H: miR-520b restrains cell growth by targeting HDAC4 in lung cancer. Thorac Cancer 9: 1249-1254, 2018 .

55. Li S, Zhang H, Ning T, Wang X, Liu R, Yang H, Han Y, Deng T, Zhou L, Zhang L, et al: miR-520b/e regulates proliferation and migration by simultaneously targeting EGFR in gastric cancer. Cell Physiol Biochem 40: 1303-1315, 2016.

56. Liang S, Chen L, Huang H and Zhi D: The experimental study of miRNA in pituitary adenomas. Turk Neurosurg 23: 721-727, 2013.

This work is licensed under a Creative Commons Attribution-NonCommercial-NoDerivatives 4.0 International (CC BY-NC-ND 4.0) License. 